\title{
Multiscale electrochemical analysis of the corrosion of titanium and nitinol for implant applications
}

\author{
J. Izquierdo ${ }^{1,2}$, M.B. González-Marreroํㅡㄹ M. Bozorg ${ }^{1}$, B.M. Fernández-Pérez ${ }^{1}$, H.C. \\ Vasconcelos $^{3}$, J.J. Santana ${ }^{4}$, R.M. Souto ${ }^{1,2, *}$
}

1 Department of Chemistry, University of La Laguna, P.O. Box 456, E-38200 La Laguna, Tenerife, Canary Islands, Spain

2 Institute of Material Science and Nanotechnology, University of La Laguna, P.O. Box 456, E-38200 La Laguna, Tenerife, Canary Islands, Spain

3 Department of Technological Sciences and Development, Azores University, 9501801 Ponta Delgada, Portugal

${ }^{4}$ Department of Process Engineering, University of Las Palmas de Gran Canaria, E35017 Las Palmas de Gran Canaria, Canary Islands, Spain

\begin{abstract}
Surface electrochemical activity of titanium and nitinol biomaterials in naturally aerated Ringer's physiological solution was investigated using potentiodynamic polarization and scanning electrochemical microscopy (SECM) techniques. SECM was operated in feedback and redox competition modes as a function of potential applied to the substrate. The kinetics of the electron transfer rate on both materials was characterized by mathematical modelling of the Z-approach curves monitored under feedback conditions. The rate constant values greatly depended on the characteristics of the passive layers formed over the metals under potentiostatic control. A more insulating film was found on nitinol when biased at low polarizations, resulting in smaller tip current increments during tip approach to the investigated surface under positive feedback and competition operation modes. However, at higher anodic polarizations, nitinol passive layers experience breakdown, and therefore tip current values reflect the release of metal cations from the biomaterial surface.
\end{abstract}

Keywords: Ti alloys; corrosion resistance; passive layers; potentiodynamic polarization; scanning electrochemical microscopy; biomaterials. 


\section{Introduction}

Metallic materials offer major advantages for their use as biomedical implants, such as high strength and wear resistance. Among them, commercially pure titanium (c.p. Ti) and several titanium-based alloys have become attractive materials due to their biocompatibility [1,2], resulting in wide use for dental applications, bone and joints replacements, etc. Their mechanical properties, particularly the low elastic modulus compared with other alloys materials such as Co-Cr or stainless steels, match better the characteristics of the healthy bone, especially when the crystallographic $\beta$ phases are predominant in the material [2,3]. Biochemical compatibility stems principally from the high corrosion resistance, which hinders the release of hazardous metal cations into the physiological environments. This protection is mainly conferred by the $\mathrm{TiO}_{2}$ layer spontaneously formed on the surface, which provides high stability even under high anodic polarization in physiological environments [4-7]. These oxide films are effectively bi-layers, with an external porous amorphous $\mathrm{TiO}_{2}$ phase that promotes osseointegration, facilitating the growth of the bone, as well as its bonding with the implant $[2,4,5,8,9]$. In addition, Ti(IV) oxides are $n$-type semi-conductors $[4,10]$, a feature regarded to inhibit electron transfer reactions with proteins such as fibrinogen, subsequently reducing eventual blood coagulation and thrombosis [11-13].

Certain biomedical applications require biomaterials showing superelastic behaviour and/or shape memory effect (SME) [14]. Among titanium-based materials, the nearly equimolar nickel-titanium alloy named nitinol has been regarded particularly suitable for those purposes. Indeed, the demand of SME biomaterials has led nitinol to be currently employed in dentistry for both endodontics tools and orthodontics arch wires [14]. In addition, nitinol is also implanted inside the human body in contact with the physiological environment, as stents in blood vessels, staples for the repair of broken bones [14], and ear implants [15]. As requisite for its biocompatibility, nitinol becomes protected from the aggressive physiological environments by the formation of a Ti-enriched oxide layer with low amounts of nickel, which is in contact with a Nienriched sub-layer [16-20]. Unfortunately, the latter renders nitinol resistance against passivity breakdown to be much poorer, resulting in the onset of pitting corrosion [1619]. As degradation progresses, $\mathrm{Ni}$ cations are released from the Ni-enriched sub-layer through pores in the outermost $\mathrm{TiO}_{2}$ film, eventually resulting in hazardous consequences due to the adverse effects associated with the $\mathrm{Ni}^{2+}$ species [21]. Furthermore, the Ni-doping of the $\mathrm{TiO}_{2}$ passive layer may compromise the 
advantageous $n$-type semiconductivity of this oxide because it contains a lower-valence metal [17].

Since the protectiveness of these materials is conferred by the passive layers formed on their surface, the study of the surface properties is crucial in order to establish their electrochemical behaviour in a physiological environment, and eventually contribute to improve their resistance. In this respect, the heterogeneity of the titanium dioxide layers present in the surfaces of both titanium and nitinol is expected to determine the behaviour of the material regarding the initiation of localized corrosion. Not only nitinol is prone to release metal ions, but also pure Ti experiences metastable pitting in physiological media [22], eventually resulting in the hazardous accumulation of titanium cations in the surrounding tissues [23]. Therefore, a comprehensive characterization of the local electrochemical surface features present in the materials with sufficient spatial resolution under in situ conditions is required for the improvement of these biomaterials.

For that purpose, Scanning Electrochemical Microscopy (SECM), which makes use of an ultramicroelectrode (UME) to raster the substrate in a given electrolyte [24], is regarded suitable because it allows acquisition of spatially-resolved electrochemical information in close vicinity of a heterogeneous electroactive surface. Previous studies of the surface electrochemical activity of titanium and titanium dioxide by SECM have been directed to characterize their local metallic and semi-conductive behaviour [2528], as well as to relate local reactivity to pitting precursor sites [29-31]. Other work was aimed to correlate the nature and composition of the passive films of new Ti-based alloys, analysed using global measurements, with their surface electrochemical response monitored by SECM operated in the feedback mode [32-35]. In contrast, characterization of nitinol surfaces with SECM has scarcely been attempted, and it was limited to monitor heterogeneous $\mathrm{pH}$ distribution during the corrosion process [36], the analysis of the heterogeneous resistance towards electric motion by alternating-current SECM [37,38], and the detection of $\mathrm{Ni}^{2+}$ cations released from active substrates [38]. On the other hand, SECM has allowed to gain quantitative information on the dependence of the electron transfer rate with the applied substrate potential and its heterogeneous distribution on some Ti-based alloys [39,40], and more recently on nitinol surfaces as well [41]. These studies have contributed to better understand the semi-conductive properties of these biomaterials. However, to our knowledge, no 
systematic study has been performed on the heterogeneous electrochemical response of the passive layer formed on $\mathrm{Ti}$ or NiTi in simulated physiological environment.

This work reports on the characterization of the passive layers formed on titanium and nitinol surfaces under potentiostatic control in the potential range typically encountered in the human body. SECM measurements were conducted in Ringer's physiological solution over a wide range of substrate polarizations, in order to investigate the electrochemical properties of the passive layers.

\section{Experimental}

\subsection{Materials and solutions}

Metallic materials were supplied by Goodfellow (Cambridge, UK). Titanium was supplied as $1 \mathrm{~mm}$ thick sheets of $99.99 \%$ purity. They were cut into $1.0 \mathrm{~mm} \times 1.9$ mm strips. The area of the titanium sample was accurately measured under an optical microscope prior to the experiments. The nitinol alloy had a nominal composition of $55 \% \mathrm{Ti}, 45 \% \mathrm{Ni}$, and was supplied by Goodfellow as $0.8 \mathrm{~mm}$ diameter wire. The cut metals were embedded in a two-component insulating resin (Epofix kit, Struers, Ballerup, Denmark). The resulting resin sleeves were circular-shaped, $3 \mathrm{~cm}$ diameter. Both the rectangular $\mathrm{Ti}$ and the circular NiTi cross-sections were faced up to be the test surfaces during the measurements. A small portion of the materials protruded at the rear of the mount in order to permit their electric connection and polarization when desired. Metal surfaces were abraded with SiC papers up to 4000 grit, and subsequently polished using alumina aqueous suspension, rinsed with water and sonicated in ethanol for 10 minutes.

Electrochemical cells were built by surrounding the 3-cm diameter mounts with sellotape to produce a small container for approximately $4 \mathrm{~mL}$ of the physiological test solution. Ringer's physiological solution was employed, containing $1.8 \mathrm{~g} / \mathrm{L} \mathrm{NaCl}, 0.42$ $\mathrm{g} / \mathrm{L} \mathrm{KCl}$ and $0.25 \mathrm{~g} / \mathrm{L} \mathrm{CaCl}_{2}$, all of them of analytical grade. No $\mathrm{pH}$-buffer was added to the solution, which was naturally aerated. Ferrocenemethanol (Sigma-Aldrich) was added to the solution in $0.5 \mathrm{mM}$ concentration to serve as redox mediator during SECM experiments. All the experiments were carried out at ambient temperature (approximately $18^{\circ} \mathrm{C}$ ). 


\subsection{Electrochemical characterization}

Conventional electrochemical measurements were performed with an Autolab bipotentiostat (Methrom, Herisau, Switzerland) controlled by personal computer, in the three-electrode configuration. In this case, the cut Ti plates were employed instead of the cross-section target embedded in the resin. The sample was confined in a homemade Teflon electrochemical cell with an o-ring pressed on the sample in order to prevent leakage, leaving a $0.63 \mathrm{~cm}^{2}$ area exposed to the electrolyte. Due to the small diameter of the nitinol wire, specimens of nitinol embedded in the epoxy sleeve were employed also for the conventional electrochemical measurements. The electrochemical cells contained a platinum auxiliary electrode, namely a platinum ring for nitinol characterization and a high surface platinum net when measuring titanium, and a $\mathrm{Ag} / \mathrm{AgCl} / 3 \mathrm{M} \mathrm{KCl}$ reference electrode. Unless otherwise mentioned, all potentials given in this work are referred to this reference electrode.

Prior to measurements, the samples were left unbiased under immersion in nonmodified Ringer's solution for 1.5 hours in order to attain a stable open circuit potential (OCP). Subsequently, Tafel polarizations were conducted from -0.25 to $+0.25 \mathrm{~V}$ vs. OCP at $0.5 \mathrm{mV} \mathrm{s}^{-1}$ scan rate. The same OCP stabilization was ensured prior to cyclic polarization measurements, which extended from $-0.25 \mathrm{~V}$ vs. OCP to $+1.20 \mathrm{~V}$ vs. $\mathrm{Ag} / \mathrm{AgCl} / 3 \mathrm{M} \mathrm{KCl}$, at $1 \mathrm{mV} \mathrm{s}^{-1}$ scan rate. All dynamic polarization measurements were done at least 3 times to establish their reproducibility.

Electrochemical impedance spectroscopy (EIS) measurements were performed at the OCP applying a sinusoidal voltage with $10 \mathrm{mV}$ amplitude and frequencies extending from $100 \mathrm{kHz}$ to $1 \mathrm{mHz}$. EIS data were analyzed in terms of equivalent circuits (EC) using ZSimpWin 2.00 software [42].

\subsection{Scanning electrochemical microscopy}

Home-made 12.5 and $25 \mu \mathrm{m}$ diameter platinum UMEs were employed. The probe fabrication procedure is described elsewhere [43]. In brief, platinum wires of the desired diameter (Goodfellow) are heated up and sealed into one end of a glasscapillary, previously closed under flame. Then, electric connection is ensured by gluing a sufficiently long copper wire of ca. $0.5 \mathrm{~mm}$ diameter to the platinum with bicomponent silver conductive epoxy (RS Components Ltd, Northants, UK). UMEs were polished down to $0.3 \mu \mathrm{m}$ alumina suspension. The final $\mathrm{Rg}$ ratio, defined as the ratio between disc diameter of the active metal and diameter of the insulating glass shielding 
the microdisc, was approximately 10, in principle enough to ensure that the hemispherical diffusion of the electroactive species from bulk solution is hindered when the tip approached a surface [24].

The SECM equipment was supplied by Sensolytics (Bochum, Germany), and it was built-up around the same Autolab bipotentiostat. Sample mounts were placed with their metal surfaces facing up. The electrochemical cell consisted of the SECM probe as first working electrode, the substrate under study connected as the second working electrode, a Pt ring as counter electrode, and the $\mathrm{Ag} / \mathrm{AgCl} / 3 \mathrm{M} \mathrm{KCl}$ reference electrode. In this way, tip and substrate potential could be controlled individually. SECM experiments were always done with the tip biased at $+0.50 \mathrm{~V}$ to ensure the electrooxidation of ferrocenemethanol under diffusion-controlled conditions. Prior to the measurements, the tip was approached to various locations over the resin surrounding the metal specimen in order to assure correct levelling of the sample. Then, either Z-approach curves, or horizontal linear and 2-D scans parallel to the metal surface, were performed while the electric condition of the substrate was maintained constant (that is, either under controlled polarization or left at its spontaneously-developed OCP). The substrate potential was progressively increased between subsequent measurements to obtain data as a function of the substrate polarization. In the experiments where the tip was moved parallel to the substrate surface, it was maintained at approximately $10 \mu \mathrm{m}$ height from the substrate. Linear scans over the titanium sample were taken along its smallest cross-section (approximately $1 \mathrm{~mm}$ length).

\section{Results and discussion}

\subsection{Potentiodynamic tests}

Conventional electrochemical measurements were performed after 1.5 hours immersion of the freshly polished metallic surfaces in Ringer`s solution to attain a stable open circuit potential (OCP). Measurements were done by triplicate at least. Typical cyclic polarization results are shown in Figure 1A, whereas Table 1 contains the quantitative information extracted from all the measurements. OCP and corrosion current density values were obtained by graphic extrapolation of the Tafel polarization plots (not shown), along with their slopes. Passive current densities (at $+0.35 \mathrm{~V}$ ) and pitting potentials were read from the cyclic polarization plots. It is found that the 
corrosion potential experienced by nitinol is $0.13 \mathrm{~V}$ more positive than for $\mathrm{Ti}$, indicating that the passive layers spontaneously developed on nitinol are nobler. The stability of the passive layer formed on nitinol was reported to depend on surface finish and treatment [16-19], which may justify that the OCP values of nitinol drifted substantially over time prior to stabilization, and the occurrence of bigger variability intervals for this material in Table 1. Altogether, it seems that nitinol surface behaves nobler than titanium in Ringer's solution when left unbiased.

A major change in the surface resistivity of the materials occurs during anodic polarization up to $+1.20 \mathrm{~V}$. While titanium does not undergo passivity breakdown within the tested potential range, nitinol exhibits pitting onset above ca. $+0.538 \mathrm{~V}$, in agreement with previous reports [16]. A distribution of anodic current spikes are observed below the pitting potential for nitinol, due to metastable pit formation and rapid repassivation, particularly evidenced in susceptible materials of small surface dimensions as in this case. Furthermore, under potentiostatic conditions below the pitting potential, and after enough induction time, some of the metastable pits may eventually evolve into propagating pits, therefore developing stable pitting corrosion. Though metastable pit formation has also been reported for the oxide layers spontaneously formed on titanium during exposure to Ringer's solution [22], they were not observed herein because the area of the Ti sample was bigger than for nitinol, and the current transients could not be distinguished above the background current. Since no attempt was made to determine the pit nucleation events on the titanium sample in Ringer's solution at this stage, a bigger surface specimen was employed.

Unlike titanium, nitinol exhibits positive hysteresis upon potential reversal, and repassivation does not occur until the potential is below the initial OCP. Therefore, the formation of a stable pit would lead to the continuous degradation of the material even at less aggressive conditions than those required to initiate the attack. This behaviour is one of the main drawbacks for the use of Ti-Ni alloys [18], because no self-healing effect operates but the implant will experience continuous degradation. This means that care must be taken to avoid the onset of corrosion reactions on the implant placed in the human body, as the highest surface potential values for metallic materials [44] are close to the pitting potentials found in this work.

In a different experimental series, the electrochemical behaviour of both metal alloys was evaluated in a modified Ringer's physiological solution, containing ferrocenemethanol and its coupled oxidized ferrocenium form. They were investigated 
in the same substrate potential range used in the SECM measurements, in order to monitor the surface electrochemical behaviour towards the redox mediator couple in conditions resembling those employed during the actual SECM measurements. The rationale was to detect any eventual effect of these redox species on the electrochemical behaviour of the two metallic materials when present in Ringer's solution as result of ferrocene-methanol oxidation at the SECM tip. The experimental procedure consisted in first dissolving ferrocenemethanol in Ringer's solution up to $0.6 \mathrm{mM}$ concentration, followed by controlled electro-oxidation of this species at $+0.50 \mathrm{~V}$ on a platinum electrode until the concentrations of the two species, ferrocene and ferrocenium, were approximately equal. Subsequently, either titanium or nitinol samples were placed at the bottom of the cell. Two linear voltammograms were recorded for each material at $1 \mathrm{mV}$ $\mathrm{s}^{-1}$, by sweeping the metal from the OCP towards $-0.40 \mathrm{~V}$, and from the OCP to +0.40 $\mathrm{V}$, respectively. These potential values are the limits for substrate polarization during the SECM measurements. Solution refreshment was performed after the cathodic scan was completed, prior to the anodic sweep, but surfaces were not treated between the two scans. The concentrations of the two species of the redox couple were accurately determined by introducing a platinum UME to record a linear voltammogram in the cell using the same scan conditions. The voltammograms depicted in Figure 1C show the electrochemical response of the two metal systems, compared to that provided by the 12.5 $\mu \mathrm{m}$ diameter noble Pt UME that was given in Figure 1B. The discontinuities in the plots originate from the two step procedure employed to record the voltammograms, always starting from the OCP. The current signal recorded at the Pt UME evidences the two diffusion-controlled current limits for either species of the redox pair. Assuming that both species have the same diffusion coefficient [39], the limiting currents measured at +0.30 and $+0.05 \mathrm{~V}$ can be employed to determine their actual concentrations. This calculation delivers $0.26 \mathrm{mM}$ for ferrocenemethanol, and $0.36 \mathrm{mM}$ for ferrocenium,

In general, when a metal sample is immersed in a solution that contains a redox couple, the OCP of this metal attains the Nernst potential of the couple. This rapidly occurs for the Pt UME, which attains $+0.178 \mathrm{~V}$ as its OCP. This potential value appears as discontinuous point in the curve given in Figure 1B, though barely observable due to the stability of the system. However, the situation differed when considering both sample surfaces. None of the OCP values for the two samples (that are observed as discontinuities on the plots of Figure 1C), occurred within the range at which transition 
from oxidation to reduction of the ferrocenemethanol + ferrocenium couple previously occurred at the Pt UME. On the contrary, both metal surfaces shifted their free potentials to more negative values, close to those encountered in the non-modified Ringer's solution. It is interesting to notice that negative currents are measured still at potentials positive with respect to the corresponding OCP values for both materials, because they are cathodic enough to sustain the electro-reduction of the ferrocenium ions present in the electrolyte. In fact, oxidation of the redox mediator occured at potentials more positive than ca. $+0.15 \mathrm{~V}$ on the nitinol milimeter-sized surface, whereas a continuous shift from measuring negative to positive currents was recorded between -0.10 and $+0.30 \mathrm{~V}$ for the titanium sample of comparable size. An abrupt current increment was observed for the nitinol sample at potentials more positive than $+0.345 \mathrm{~V}$, attributable to the onset of pitting corrosion. On the other hand, increasing more negative current values were monitored on both materials when polarized from the OCP to more negative values, though nitinol attains a constant current plateau at potentials below ca. $-0.10 \mathrm{~V}$. These observations can be summarized as it follows: a) electro-reduction of ferrocenium and regeneration of the redox mediator occurs on nitinol with a constant rate at potentials negative to $-0.10 \mathrm{~V}$, whereas this reaction is hindered on the pure titanium surface in this potential range; and b) competitive effects between the Pt UME and the substrate may affect the current responses of the tip and the substrate for potential values above $+0.15 \mathrm{~V}$ on nitinol, and also on titanium though in a smaller extent. However, these observations must be regarded at this stage only to be an anticipation of the actual behaviour of the systems during SECM experiments, because these materials may more effectively form passive layers on their surface as the potential shift is produced at a slower pace. Besides, the heterogeneous behaviour cannot be explored with conventional measurements that average the electrochemical response of the exposed surface, thus further supporting the need of the local electrochemical analysis for the characterization of these passive surfaces.

\subsection{Electrochemical impedance tests}

Electrochemical impedance spectroscopy (EIS) measurements were performed at open circuit potential conditions after the materials attained a stable open circuit potential in Ringer's solution. Figure 2 depicts the Bode impedance diagrams for titanium and nitinol. They display two time constants, a behaviour corresponding to a metal covered with an oxide film with duplex structure, with a thin compact inner layer 
and a somewhat more porous external layer that may be eventually penetrated by the electrolyte [45]. Accordingly, the spectra were analyzed in terms of the equivalent circuit proposed for an unsealed inhomogeneous surface film [46] that is shown in Figure 3. The barrier characteristics of the inner oxide layer towards electrolyte penetration dominates the impedance response in the low-frequency range (described by the time constant $R_{\mathrm{ox}} Q_{\mathrm{ox}}$ ), whereas the charge transfer process in the surface of the materials is observed at higher frequencies (represented by $R_{\mathrm{ct}}$ and $Q_{\mathrm{dl}}$ ). The use of a constant phase element (CPE), $Q$, was required to account for the non-ideal capacitive response observed as a depressed semicircle when the spectra were plotted in the corresponding Nyquist diagrams (not shown here). The CPE originates from surface roughness and inhomogeneities present in the titanium oxide layers at the microscopic level $[47,48]$, and it is given by:

$$
Z_{(C P E)}=\frac{1}{Y_{0}(j \omega)^{n}}
$$

where $\omega$ is the angular frequency and $Y_{0}$ is a constant, and the value of the exponent $n$ indicates the deviation from ideal capacitive behaviour (e.g., when $n=1$ ). From the CPE parameters, capacitance values can be derived from using [49]:

$$
C=\left(R^{1-n} Q\right)^{1 / n}
$$

Assuming that the parallel-plate capacitor equation can apply to the capacitance of the oxide layers, their thickness can be estimated using:

$$
C=\frac{\varepsilon \varepsilon_{0} A}{d}
$$

where $\varepsilon$ is the dielectric constant of the oxide and $\varepsilon_{0}$ the dielectric permittivity of vacuum, $A$ is the effective area, and $d$ the thickness of the oxide layer [50]. Since XPS data show that the nitinol surface is spontaneously covered by a inner Ti dioxide likewise pure titanium, whereas the outer layer is a mixed $\mathrm{TiO}_{2}$ and $\mathrm{NiO}$ layer [20], $\varepsilon=$ 65 was assumed in this work, which is the value for $\mathrm{TiO}_{2}$ [51], and the surface roughness factor as unity. Nevertheless, it must be taken in account that the oxides formed on this alloys always contain a certain fraction of $\mathrm{Ni}$. Table 3 gives the estimated thickness of the oxide films spontaneously formed on the two materials in Ringer's solution. The values obtained for the inner barrier of nitinol $(1.1 \mathrm{~nm})$ and titanium (namely $4.4 \mathrm{~nm}$ ) agree well with data in the literature [20,51]. Therefore, 
significantly thinner layers, both for the inner barrier film and the outer porous layer, are formed on nitinol compared to titanium.

\subsection{Scanning electrochemical microscopy tests}

The characterization of electrochemically active surfaces by SECM is based on the monitoring an electrochemical current with the UME tip. In this work, ferrocenemethanol was added to Ringer's physiological solution as redox mediator for amperometric feedback operation [24]. Ferrocenemethanol is an organometallic iron (II) complex which is oxidized into its ferrocenium ion form $\left(\mathrm{Fc}^{+}\right)$at a platinum microdisc when biased above $+0.2 \mathrm{~V}$ [40], being Fc the stable form below $+0.1 \mathrm{~V}$. All the SECM experiments done here were conducted with the tip polarized at $+0.50 \mathrm{~V}$, ensuring diffusion control for Fc electro-oxidation. A micrometer-sized (10-25 $\mu \mathrm{m}$ dia.) platinum microdisc was sealed at the center of a greater insulating glass disc, that the ratio between the diameters of the glass and the conductive disc (i.e., $R g$ ratio) was between ca. 10 to 100 [24]. This allowed the electrochemical response of the electroactive species to solely depend on its diffusion and interaction with the substrate location just underneath the UME tip, facilitating the local electrochemical characterization of that site [52]. The precise positioning of the sample surface with respect to the tip was established by recording Z-approach curves to various sites on the insulating resin surrounding the metallic sample at either side. In this way, negative feedback operation was ensured, and the tip was moved towards the substrate until current was $55 \%$ of the limiting current value measured in bulk solution. This corresponds to ca. $7.5 \mu \mathrm{m}$ tipsample distance (i.e., normalized distance 1.2) [24,39-41].

The first series of experiments consisted in recording Z-approach curves over the metal samples subjected to varying polarization. Thus, the SECM tip was first moved parallel to the surface until placed over the centre of the metal, subsequently retracted from it, and then approached to record the corresponding Z-approach curves at slower rate $\left(2 \mu \mathrm{m} \mathrm{s}^{-1}\right)$. Z-approach curves were first recorded while the substrate remained unbiased (i.e., at its spontaneous OCP), and then sequentially biased at increasing fixed substrate potential, starting from $-0.40 \mathrm{~V}$. A selection of Z-approach curves recorded over the two materials are shown in Figure 4. Normalized current values were determined by dividing the measured current values by Ilim. Analogously, the tip-sample distance $d$ was also normalized considering the tip radius $a$ (i.e., normalized distance, $L$ $=d / a)$. The figure also includes the theoretical curves determined for purely conductive 
and insulating surfaces in the feedback mode $[24,39,40]$. When the polarized UME approaches to a conductive material (or a conductive site of a heterogeneous material), which presents a sufficiently cathodic potential, the $\mathrm{Fc}^{+}$species electrogenerated at the tip is reduced back into Fc at the surface, thus increasing the concentration of this species at the location below the UME. As result, there is an accumulation of Fc species, and consequently a concentration increment, thus increasing the tip current as depicted in Figure 5A (positive feedback). Conversely, if the site below the tip is not conductive under the operating conditions, not only Fc will be consumed at the tip, but the substrate will also hinder the diffusion of this species from the bulk electrolyte to the UME. This leads to a decrease in both Fc concentration and tip current as the tip approaches the substrate (negative feedback, see Figure 5B). In this case, the faradaic current measured at the UME would exclusively respond to the topography of the investigated surface [24]. A combination of both the positive and negative feedback modes is possible as well, since the rate for the regeneration of the mediator sketched in Figure 5A depends on the conductivity and catalytic characteristics of the substrate surface [39-41]. This would result in a variety of intermediate mixed responses, which can be modelled as a function of $R g$, the normalized tip-sample distance, and the electron transfer kinetic constant $\left(k_{\text {eff }}\right)$ at the substrate surface [53]. This allows the quantitative estimation of the keff values from the comparison the experimental and modelled curves for tip-sample separations bigger than 0.1 times the Pt microdisc radius. Such calculation requires the diffusion coefficient of the redox mediator to be known (e.g., $6 \times 10^{-6} \mathrm{~cm}^{2} \mathrm{~s}^{-1}$ for ferrocenemethanol [40]). Hence, finite keff values will result from either slow kinetics for the electron transfer at the surface or weak electromotive force, and the concentration of the mediator cannot increase steadily due to regeneration as the tip approaches the surface. This occurs in partially conductive passive surfaces at which electron transfer is hindered [54-56].

A new situation arises when the substrate potential is further increased into a range where $\mathrm{Fc}^{+}$is the stable species, its electro-reduction back to $\mathrm{Fc}$ cannot longer happen at the surface. Conversely, if the surface is electroactive and/or sufficiently anodically polarized, the electro-oxidation of the Fc will also occur at the substrate. As result, the concentration of the redox mediator decreases, and consequently the tip current as well. This mechanism is known as the redox-competition mode (see Figure 5C) [57]. Again, a combination of negative feedback and competition modes can 
operate, though in this case both phenomena would lead to tip current depletion, that will be more pronounced when competition is established.

In principle, positive feedback behaviour may be expected at substrate potentials below $+0.15 \mathrm{~V}$, whereas competitive effects may appear above this value, along with eventually mixed negative feedback-type response for any given substrate potential. When pure titanium is left unbiased, the tip current increases during tip approach, and a positive feedback effect is obtained, whereas the signals recorded on nitinol barely reflect any effects, as given by the black curves in Figures 2A and 2B. From these measurements, $k_{\text {eff }}=1.34 \times 10^{-3} \mathrm{~cm} \mathrm{~s}^{-1}$ on nitinol, whereas the response obtained on pure titanium closely matches the theoretical curve for a perfectly conductive material. Since the spontaneous open circuit potential of both metals is negative enough to promote the regeneration of the redox mediator (cf. Table 1 and Figure 1C), the different behaviour found for the two materials must originate from differences in their conductive properties. The oxide layer formed on titanium is $n$-type semiconductor, so free electrons are available in the conduction band to be donated to the ferrocenium species $[25,26]$. The result obtained here at the OCP on Ti differs from the negative feedback (or at least mixed) behaviour previously found for bulk titanium surfaces of bigger dimensions [27,28,32]. Not to avail, the titanium surface is known to exhibit heterogeneous conductivity and the smaller surface dimensions herein employed may induce the active spots to be more easily located when doing SECM experiments, possibly along with the different tip approximation rates employed here. Conversely, although the passive layer formed on nitinol is mainly constituted by the same $\mathrm{TiO}_{2}$ compound [20], its doping with $\mathrm{Ni}^{2+}$ cations may render partial loss of the $n$-type semiconductive behaviour [17]. Shabalovskaya et al. [58] showed the conductivity of nitinol surface oxide layers is characteristic of wide band gap semiconductors, closely related to the conductivity of pure $\mathrm{TiO}_{2}$. Yet, the oxide layers on this materials show a great variability in their conductivity depending on the Ni state and concentration, leading to different degrees of the spontaneous doping of the semiconductive Ti dioxide with oxygen vacancies and with $\mathrm{Ni}$ [58]. This would result in a smaller electron transfer rate and weaker positive feedback effect, limited by the small active sites which may appear on the surface. As result, the tip response is described by a mixed behaviour between positive and negative feedback effects. In any case, the results obtained over this kind of heterogeneous systems on scattered locations could correspond to single local features instead of a more general behaviour, especially at the OCP conditions when no electric 
state is imposed to the system. Heterogeneity of the systems will be discussed later on the basis of constant-distance SECM measurements.

Substrate polarization effectively alters the current response monitored during the $Z$-approach curves compared to the spontaneous situation. As predicted, tip current increases when the tip approaches the cathodically polarized metals as result of the positive feedback effect, and the opposite trend is mainly observed when the metals are anodically biased. However, the change between the two behaviours occurs in a more progressive trend for the titanium sample (cf. Figure 4A) compared to that observed on nitinol (Figure 4B). In the case of titanium, purely positive feedback was observed at potentials below $-0.10 \mathrm{~V}$ (not shown), followed by a steady decay of the tip current when the substrate potential was shifted from -0.10 to $+0.10 \mathrm{~V}$. It has been suggested that electrochemical reduction of $\mathrm{Ti}(\mathrm{IV})$ to $\mathrm{Ti}(\mathrm{III})$ and simultaneous hydrogen coadsorption may occur with increasing cathodic polarization in this potential range, with the result of a modification in the surface properties of the material by the introduction of a new band within the bandgap $[27,28]$. Hence, such higher hydrogen content in the oxide layer and sublayers at the more negative polarizations would facilitate electron donation, reaching the conductive limit below $-0.10 \mathrm{~V}$ substrate polarization. Conversely, despite 0.00 and $+0.05 \mathrm{~V}$ are still cathodic enough to sustain ferrocenemethanol regeneration and correspondingly a positive feedback effect, tip current increases less than for bigger cathodic polarizations. On the other hand, a mixed effect can affect the system response when titanium polarization is greater than $+0.20 \mathrm{~V}$. However, the growth and metastable breakdown of the passive layer may influence this result. In fact, while the curve determined at $+0.35 \mathrm{~V}$ is almost superimposed to the theoretical curve resulting from the approximation to an insulator, that recorded for $+0.20 \mathrm{~V}$ substrate polarization shows even smaller currents, evidencing the occurrence of a further phenomenon which is absent at higher anodic polarizations. This is attributed to the presence of a perfectly insulating passive layer which can only grow when sufficient anodic potential is applied, whereas below this value the surface behaves as a conductor capable to experience the competitive effect.

In general, the changes in the $Z$-approach curves with substrate polarization were smaller in the case of nitinol. Indeed, none of the Z-approach curves followed the purely conductive behaviour for positive feedback, and the experiments performed in the potential range where the mixed effect would be expected still displayed the typical trend for an insulator. These results suggest the formation of a more insulating passive 
layer on nitinol, which hinders electron donation, and is less sensitive to changes in the potential applied to the substrate. Furthermore, electron acceptance in the positive potential range seems to be similarly hindered.

These features can be better analyzed from the tip current increment or decay determined from the normalized tip current $I / I_{\lim }$ at fixed tip-substrate distance. An arbitrary distance $L=d / a=4$ was chosen, as it would correspond to the minimum distance reached during tip approximation towards the nitinol surface. The $I / I_{\lim }$ data are plotted in Figure 6A as a function of the substrate polarization. The limits for pure positive and negative feedback behaviours, corresponding to conductive and insulating substrates, are also indicated in the plot. The current values close to the higher limit (i.e., positive feedback, conducting behaviour) reflect almost purely conductive behaviour of the surface that favours electron donation to the ferrocenium ion. It must be noticed that tip currents bigger than the theoretical value for purely positive feedback were actually found, though this would be a physical impossibility provided the faradaic current at the tip only depends on the concentration of the redox couple of the mediator species under diffusion-controlled conditions. Uncertainties may occur in the actual tipsample distance, or most likely in the tip current (due to the small values in the order of a few pA), that would affect the recorded tip currents.

Conversely, experimental values close to the lower limit (i.e., negative feedback, insulating behaviour), indicate that the metal surface behaves as an insulator for the regeneration of the mediator, and the ferrocenemethanol mediator is not consumed there. When experimental data are found below the lowest limit, current decay happens not only as result of the negative feedback effect, but also due to the competition between the conductive sample and the UME tip for the electro-oxidation of the mediator. Only the experimental curves resulting from mixed behaviours, thus with normalized current values in Figure 6A comprised between both limits, can be considered for the mathematical calculation of $k_{\text {eff }}$ values. Results from such calculation are plotted in Figure 6B, by comparing these experimental curves with theoretical data available in the literature [54].

Figure $6 \mathrm{~B}$ also shows the potential regions in which insulating (i.e., pure negative feedback) and conductive (due to either pure positive feedback or additional competition effects) responses occurred. Some differences in the behaviour of the two metallic materials can thus be observed. Whereas most of the data obtained for nitinol correspond to mixed positive-negative feedback behaviour, such behaviour is only 
found in three data points for titanium. That is, nitinol undergoes spontaneous degradation at lower rate during immersion in Ringer's solution due to its nobler passive layer. Thereby, this nobler character is accompanied by more electrically insulating properties for the surface layer which hinder electron transfer at potentials around the OCP (namely -0.21 and $-0.34 \mathrm{~V}$ for nitinol and titanium, respectively). The electron transfer reaction is a part of the whole electrochemical corrosion process, and it is favoured on the more $n$-type semi-conductive surface layer of titanium compared to nitinol, as the electrons available in the conduction bands are progressively removed with the application of an increasing anodic polarization to the substrate. For $+0.10 \mathrm{~V}$ substrate polarization, keff values fall to almost zero for both surfaces, regardless its electrochemical properties, probably due to thermodynamic conditions rather than kinetic hindrance by the passive layer. At substrate potentials above $+0.10 \mathrm{~V}$, the occurrence of competitive effects between the tip and the substrate originate the current decrease when the tip approaches the sample, but this effect is different for the two materials. Whereas the values of the tip current decrease steadily up to $+0.30 \mathrm{~V}$ substrate potential, the more insulating passive layer formed on nitinol is responsible for the very small effect of substrate polarization on the tip current over this potential range. That is, the current decrease falls below the values corresponding to the negative feedback effect, and nitinol only exhibits a mixed response when biased at $+0.30 \mathrm{~V}$. Finally, the normalized currents registered over titanium at the distance of maximum approximation exhibit a sharp increment when biased between +0.35 and $+0.40 \mathrm{~V}$, as if the phenomena responsible for current depletion were somewhat hindered at high anodic polarizations. This can be explained considering that these potential values lie in the potential range where active-passive transition occurs according to Figure $1 \mathrm{~A}$, and the passive layer is then further stabilized. Eventually, hindrance of the competitive effect then occurs, and the negative feedback response is the only process responsible for the measured current decrease. This observation is supported by the decay observed in the overall current flowing through the substrate, which was recorded simultaneously to the $Z$-approach curves. No breakdown of the passive layer was observed for the titanium sample, though metastable current transients were detected at some potential values located in the passive range of the materia. The trend is different for nitinol, due to the onset of pitting corrosion above $+0.35 \mathrm{~V}$.

In fact, when active corrosion occurs at the substrate, metal cations (mainly $\mathrm{Ni}^{2+}$ in the case of nitinol) releasing from the surface as a result of the anodic dissolution 
may also react at the UME. Then, an increase of the tip current should occur when located near the corroding source. In contrast, we have reported that the generation of low-valence metal cations from anodically polarized surfaces undergoing anodic dissolution may lead to the electro-oxidation of such cations at the surface itself, depending on the substrate nature and the electrolytic environment [59,60]. The subsequent SECM response will reflect the diffusion of those low-valence cations into the surrounding regions, thus being detected over the insulating material in which metal is embedded, but not close to the metal itself where the low-valence cations are oxidized, and therefore consumed. Figure 1D depicts this substrate generation-tip collection (SG-TC) mode considering the occurrence of an active degradation process on nitinol that produces $\mathrm{Ni}^{2+}$ cations, which are oxidized into $\mathrm{Ni}(\mathrm{IV})$ species at both the tip and the substrate. The contribution of ferrocenemethanol to the tip current can be considered negligible if vigorous anodic metal dissolution occurs.

SECM was also employed to record scan lines through the exposed metal sections in order to image any heterogeneous distribution of electrochemical activity on the materials. Figure 7 shows selected plots obtained at various substrate polarizations given as normalized current values. Again, transition from positive to negative feedback behaviours, and even competitive effects are observed. This is evidenced by the transition from bigger to smaller tip currents with the application of more positive potentials to the substrates. As readily seen, the tip responses over the resin and the metal are almost the same at $+0.10 \mathrm{~V}$ substrate potential. As result, electron transfer does not occur on the metal, originating a negative feedback as observed in Figure 6. Regarding nitinol, a sharper variation with substrate potential is observed in Figure 7B, an observation that seems to contradict the conclusions derived above on the basis of the $Z$-approach curves. That is, the data in Figure 7 apparently support that nitinol is the material exhibiting bigger changes with polarization, which would correspond to the most electrically conductive material with facilitated electron transfer reactions. Conversely, the results for titanium are consistent with the trends observed above from the $Z$-approach curves, since the maximum currents in Figure 7A do not exceed those registered in Figures 4A and 6. Despite some tilt of the samples may occur, and the difference in the actual tip-substrate distance due to the different diameter of the UMEs employed to record the $Z$-approach curves and the scan lines (respectively 25 and 12.5 $\mu \mathrm{m}$ dia.), the described apparent discrepancies on nitinol surface conductivity between the two experiments should be mainly attributed to the heterogeneous distribution of the 
surface activity on the material. Indeed, a more heterogeneous distribution for nitinol is evidenced by the numerous current spikes found as the tip travelled over the metal cross-section. Previous reports suggest that the positive feedback effect recorded on $\mathrm{TiO}_{2}$ layers using ferrocenemethanol may occur through the donation of one electron from $\mathrm{Ti}(\mathrm{III})$ species to the ferrocenium ion, forming $\mathrm{Ti}(\mathrm{IV})$ and regenerating ferrocenemethanol [26,27]. However, for surfaces where this process is not homogeneously favoured, electron exchange would preferentially occur at the grain boundaries where impurities are accumulated, especially under the application of high cathodic potentials. This may happen on the nitinol surface, and the heterogeneous response given in Figure 7B probably reflects this process. Since variable conductivity of nitinol surfaces has been attributed to different degrees of the doping of the semiconductive $\mathrm{TiO}_{2}$ with oxygen vacancies and with $\mathrm{Ni}$ [58], this should be affected by the polarization applied to the material. As these oxides are growing from the surface of nitinol, there is always a certain amount of Ni present, and thicker oxide films may lead inevitably to $\mathrm{Ni}$ accumulation in form of single atoms, atomic clusters or $\mathrm{Ni}$ particulates [58].

The heterogeneous nature of the materials was also investigated by scanning the tip at a fixed distance over the complete metal surface while polarized at a fixed potential value. In this case, suitable travel lengths were selected for each sample. Selected SECM images are shown in Figure 8. The contours of the two metallic surfaces are resolved in the maps, especially under cathodic polarization, due to the occurrence of a strong positive feedback effect. Conversely, tip currents smaller than those registered in bulk solution are monitored when negative feedback operates. A pure positive feedback effect is observed for the two metals biased at -0.40 and $-0.20 \mathrm{~V}$, more intense over titanium, in agreement with the Z-approach curves in Figures 4 and 6. Though the electrochemical activity is heterogeneously distributed on both metals, greater variations are observed over nitinol. Subsequent polarization at $0.00 \mathrm{~V}$ reveals different behaviours for the two metals. On the one hand, some areas of the nitinol surface remain electrochemically active and produce ferrocenemethanol regeneration (i.e., positive feedback), as it was previously observed along the linear scan of Figure 5 and at the site where the Z-approach curve given in Figure 4 was measured. Meanwhile, other regions of the sample simply did not sustain electron transfer resulting in a negative feedback effect, effectively originating tip currents very close to those recorded over the surrounding insulating resin. Under the same conditions, titanium still shows a 
positive feedback response at the bottom of the image, at the beginning of the $Y$ axis. Taking into account that the scans were acquired as a sequence of linear scans extending from $Y=0$ to $Y=2200 \mu \mathrm{m}$, this positive feedback effect appearing precisely at the beginning of the scan most probably arises from a temporary condition, rather than a spatial distribution of the surface electrochemical activity. It is concluded that the insulating properties of the passive layer formed on titanium, and thereby its protective ability, are actually increasing with time along the measurements. That is, the metal surface was initially more conductive and became more insulating as scan collection advanced, therefore hindering the redox mediator regeneration at the middle and final stages of image acquisition. This agrees well with the increase in the mean substrate current at $+0.10 \mathrm{~V}$ observed for titanium only when the Z-approach curves were recorded using a sequential procedure, as described in the supporting information. That is, the longer time required for recording the linear scans allowed sufficient growth of the passive layer to be noticed. Indeed, the substrate current recorded during the acquisition of the 2-D maps also supports that the growth of the passive layer precisely occurs when tip current decreases, as further discussed in the supporting information.

Further polarization at $+0.20 \mathrm{~V}$ led to the observation of regions on the metals at which the measured tip currents were smaller than those registered over the adjacent insulating resin. Though the insulating resin was polished to the same degree than the metal, differences in hardness between the materials may account for some small differences in their surface levels. Consequently, lower tip currents are detected probably due to the onset of a competitive effect between the tip and the substrate for the electro-oxidation of ferrocenemethanol, which also results in a heterogeneous distribution of the surface electrochemical activity.

It has been previously mentioned that nitinol suffered from pitting corrosion under the potentiostatic conditions reached during the SECM measurements for the higher anodic polarizations of +0.35 and $+0.40 \mathrm{~V}$, and this process should influence the UME response. The effect of high positive polarization for nitinol on the currents sensed at the tip are displayed in Figure 9 as Z-approach curves (Figure 9A), scan lines (Figure 9B), and 2D maps (Figure 9C), respectively. Absolute tip current values ranging from 10 to $50 \mathrm{nA}$ were measured (that is, dimensionless normalized current values of 15 to 75), much greater than any other values recorded using ferrocenemethanol as mediator in the previous experiments. Unlike nitinol, the surface of titanium mainly showed a competitive effect during polarization at $+0.40 \mathrm{~V}$ (cf. Figure 9D), with tip 
current values over the metal smaller than those measured over the insulating resin. Therefore, it is likely that the lower conductivity encountered on the titanium surface at this potential range in Figure 4, evidencing an almost insulating nature of the substrate apparently due to an active-passive transition, was either a local phenomenon occurring just below the tip, or an stage of passive film formation leading to its thickening and further stabilization, becoming more conductive after few minutes. Indeed, this anodic polarization originated a more conductive behaviour of the material as shown by SECM experiments using different mediators and supporting electrolytes [25,39], which suggests that the titanium passive surface more likely exhibits activity towards electron transfer, though heterogeneously distributed. On the other hand, the application of positive potentials to the metal may favour the enrichment of the passive layer in Ti(IV) rather than $\mathrm{Ti}(\mathrm{III})$, so the tendency to accept electrons and promote competitive effects would be enhanced.

Regarding the characteristic tip current increase effect observed above nitinol, it must be noticed that the bigger tip current values are always found beyond the metal limits in both linear and 2-D scans, whereas smaller tip current responses are found over the active area of the substrate. Since the metal should, in principle, experience negative feedback and competitive effects at these substrate polarizations (analogously to pure titanium), the electrochemical reaction responsible for this behaviour cannot be attributed to the regeneration of the redox mediator, which cannot happen on the metal surface biased at this anodic potential. Furthermore, this sharp increase in the tip current is only detected when active anodic degradation of nitinol occurred (evidenced by the increment produced in the current recorded from the substrate). A similar behaviour was previously reported for iron-based materials [59,60], and it was attributed to the release of aqueous ferrous species from the surface as result of the corrosion process, and either its subsequent diffusion into bulk solution or its electro-oxidation into ferric cations at the metal surface itself. The same can be proposed for nitinol. That is, once the material starts corroding due to the nucleation and growth of a stable pit, the sample will continue corroding and releasing soluble metal species into the solution, which may be detected by the tip operating in the SG-TC mode. However, when the tip passes above the metal, these species may be adsorbed and even oxidized at the metallic surface, which remains anodic due to the externally imposed polarization. Thus, a competitive effect occurs, and no electroactive species can be detected at the tip. Conversely, when measuring with the tip placed above the insulating resin in the vicinity of the metal, the 
diffusing metal species are detected, eventually leading to the measurement of tip currents bigger than those for ferrocenemethanol if sufficiently high amounts of the metal ions are released from the corroding surface.

Though the occurrence of the SG-TC mode operation is sustained by the data, identification of the species responsible for this effect remains under speculation. In order to gain new information on this matter, an additional experiment was conducted using a nitinol sample immersed in the modified Ringer's solution containing ferrocenemethanol while it was polarized at $+0.40 \mathrm{~V}$ (i.e., a potential value high enough for nitinol to undergo pitting corrosion). After the UME was placed at $15 \mu \mathrm{m}$ distance from an arbitrary position close to the centre of the nitinol sample, five consecutive cyclic voltammograms were recorded at the tip. For the sake of clarity, Figure 8 only depicts the first voltammogram recorded in this series, though their corresponding peak potentials are summarized in Table 4. From the drift of the peak potentials, it is considered that the electrochemical reaction occurring at the UME involves protons or hydroxyl ions, because they can be attributed to the highly localized $\mathrm{pH}$ distributions which may result from the corrosion process itself [36]. Moreover, the presence of soluble metal cations due to the corrosion process is known to be heterogeneously distributed, and potential of any oxidizable system involving such cations will also depend on their concentration. It is established that nickel dissolves preferentially from corroding nitinol surfaces [21], and the only soluble species found at this potential and moderate $\mathrm{pH}$ during the corrosion of pure nickel is $\mathrm{Ni}^{2+}$ [61]. Hence, reactions (4) to (6), given together with their standard reduction potential values, are considered acceptable candidates for the process:

$$
\begin{array}{ll}
\mathrm{Ni}^{2+}+2 \mathrm{H}_{2} \mathrm{O} \rightleftarrows \mathrm{NiO}_{2}(\mathrm{~s})+4 \mathrm{H}^{+}+2 \mathrm{e}^{-} & E^{0}=1.593 \mathrm{~V} \text { vs. NHE } \\
2 \mathrm{Ni}^{2+}+3 \mathrm{H}_{2} \mathrm{O} \rightleftarrows \mathrm{Ni}_{2} \mathrm{O}_{3}(\mathrm{~s})+6 \mathrm{H}^{+}+2 \mathrm{e}^{-} & E^{0}=1.753 \mathrm{~V} \text { vs. NHE } \\
3 \mathrm{Ni}^{2+}+4 \mathrm{H}_{2} \mathrm{O} \rightleftarrows \mathrm{Ni}_{3} \mathrm{O}_{4}(\mathrm{~s})+8 \mathrm{H}^{+}+2 \mathrm{e}^{-} & E^{0}=1.977 \mathrm{~V} \text { vs. NHE }
\end{array}
$$

The oxidation reactions given by equations (1) and (2) lead to the formation of nickel (IV) and nickel (III) oxides, whereas a mixed oxide is obtained through reaction (6). The standard potential values of these redox pairs are strongly influenced by the solution $\mathrm{pH}$, so under certain proton activity in the solution, the average potential 
between the anodic and cathodic spikes seen in the Table 4 would relate well to the potential values given by equations (4) - (6). In this way, alkaline $\mathrm{pH}$ between 9 and 10 will be needed to produce nickel (IV) oxide at this tip potential, whereas almost neutral solutions are required for nickel (III) and mixed oxides. Alkalization around cathodic areas is typically observed during corrosion processes, while acidification may occur at the anodes resulting from the hydrolysis of the released metal cations [62]. Further work will be required to quantitatively explore the actual $\mathrm{pH}$ distribution produced during the anodic degradation of this material, and its correlation with the release of nickel species, though at this stage, nickel (II) can be regarded to be the soluble species released from the surface.

\section{Conclusions}

The electrochemical surface behaviour of biomedical nitinol material has been investigated during exposure to physiological Ringer's solution and compared with pure titanium. The slower corrosion rate shown by nitinol in this environment arises from the development of a more insulating and nobler passive layer. Unfortunately, this nobler passive layer may undergo pitting corrosion, resulting in the hazardous release of corrosion products, at quite low anodic polarizations.

SECM has allowed the conductive and semi-conductive properties of both materials to be related to their corrosion resistance, evidencing that heterogeneous processes in the micrometer scale strongly determine their electrochemical behaviour. It has been found that the electron transfer ability of the surfaces is heterogeneously distributed on the surface of the materials, and depends on the potential applied to the substrate. Additionally, electron transfer reactions are also affected by the duration of exposure to the aqueous test environment, and the duration of the polarization applied to the substrate. Therefore, in situ monitoring of evolution of the surface behaviour with the elapse of time is regarded critical. The differences in the semi-conductive properties of the oxide layers formed on both metallic materials are influential for the electrochemical response related to electron transfer on the surface, and its dependence towards the substrate potential.

\section{Acknowledgments}


This work was supported by the Spanish Ministry of Economy and Competitiveness (MINECO, Madrid, Spain), jointly with the European Regional Development Fund (Brussels, Belgium), under Grant CTQ2012-36787. The award of Research Training Grants to J.I. by the Spanish Ministry of Education (Programa de Formación de Personal Investigador, Madrid, Spain), and to B.M.F.-P. by Obra Social La Caixa - Fundación Cajacanarias (Santa Cruz de Tenerife, Spain) are greatly acknowledged.

\section{References}

[1] M. Geetha, A.K. Singh, R. Asokamani, A.K. Gogia, Ti based biomaterials, the ultimate choice for orthopaedic implants - A review, Progress in Materials Science 54 (2009) 397-425.

[2] Y. Li, C. Yang, H. Zhao, S. Qu, X. Li, Y. Li, New developments of Ti-based alloys for biomedical applications, Materials 7 (2014) 1709-1800.

[3] M. Niinomi, M. Nakai, J. Hieda, Development of new metallic alloys for biomedical applications, Acta Biomaterialia 8 (2012) 3888-3903.

[4] J. Pan, Oxide film characterization by means of electrochemical impedance spectroscopy and surface analysis, Dissertation, Department of Materials Science and Engineering, Royal Institute of Technology, Stockholm, Sweden, 1996.

[5] E. Alkhateeb, S. Virtanen, Influence of surface self-modification in Ringer's solution on the passive behavior of titanium, Journal of Biomedical Materials Research Part A 75A (2005) 934-940.

[6] V.A. Alves, R.Q. Reis , I.C.B. Santos, D.G. Souza, T. de F. Gonçalves, M.A. Pereira-da-Silva, A. Rossi, L.A. da Silva, In situ impedance spectroscopy study of the electrochemical corrosion of $\mathrm{Ti}$ and $\mathrm{Ti}-6 \mathrm{Al}-4 \mathrm{~V}$ in simulated body fluid at 25 ${ }^{\circ} \mathrm{C}$ and $37^{\circ} \mathrm{C}$, Corrosion Science 51 (2009) 2473-2482.

[7] N. Schiffa, B. Grosgogeata, M. Lissaca, F. Dalard, Influence of fluoride content and $\mathrm{pH}$ on the corrosion resistance of titanium and its alloys, Biomaterials 23 (2002) 1995-2002.

[8] T. Albrektsson, P.I. Brånemark, H.-A. Hansson, L. Lindström, Osseointegrated titanium implants, Acta Orthopaedica Scandinavica 52 (1981) 155-170.

[9] F. Rosalbino, D. Macciò, P. Giannoni, R. Quarto, A. Saccone, Study of the in vitro corrosion behavior and biocompatibility of $\mathrm{Zr}-2.5 \mathrm{Nb}$ and $\mathrm{Zr}-1.5 \mathrm{Nb}-1 \mathrm{Ta}$ 
(at.\%) crystalline alloys, Journal of Materials Science: Materials in Medicine 22 (2011) 1293-1302.

[10] K. Azumi, M. Seo, Changes in electrochemical properties of the anodic oxide film formed on titanium during potential sweep, Corrosion Science 43 (2001) 533-546.

[11] A. Bolz, M. Amon, C. Ozbek, B. Heublein, M. Schaldach, Coating of cardiovascular stents with a semiconductor to improve their hemocompatibility, Texas Heart Institute Journal 23 (1996) 162-166.

[12] P. Yang, S.C.H. Kwok, R.K.Y. Fu, Y.X. Leng, J. Wang, G.J. Wan, N. Huang, Y. Leng, P.K. Chu, Structure and properties of annealed amorphous hydrogenated carbon (a-C:H) films for biomedical applications, Surface and Coatings Technology 177-178 (2004) 747-751.

[13] C.-C. Shih, C.-M. Shih, Y.-Y. Su, R.A. Gerhardt, S.-J. Lin, The interaction of selected semiconducting biomaterials with platelet-rich plasma and whole blood, Journal of Biomedical Materials Research A 74 (2005) 325-337.

[14] W.M. Huang, C.L. Song, Y.Q. Fu, C.C. Wang, Y. Zhao, H. Purnawali, H.B. Lu, C. Tang. Z. Ding, J.L. Zhang, Shaping tissue with shape memory materials, Advanced Drug Delivery Reviews 65 (2013) 515-535.

[15] G.P. Rajan, R.H. Eikelboom, K.S. Anandacoomaraswamy, M.D. Atlas, In vivo performance of the nitinol shape-memory stapes prosthesis during hearing restoration surgery in otosclerosis: A first report, Journal of Biomedical Materials Research B 72 (2005) 305-309.

[16] W.M. Carroll, M.J. Kelly, Corrosion behavior of nitinol wires in body fluid environments, Journal of Biomedical Materials Research A 67 (2003) 1123-1130.

[17] S.A. Shabalovskaya, G.C. Rondelli, A.L. Undisz, J.W. Anderegg, T.D. Burleigh, M.E. Rettenmayr, The electrochemical characteristics of native nitinol surfaces, Biomaterials 30 (2009) 3662-3671.

[18] C.W. Chan, H.C. Man, T.M. Yue, Effect of post-weld heat-treatment on the oxide film and corrosion behaviour of laser-welded shape memory NiTi wires, Corrosion Science 56 (2012) 158-167.

[19] I. Milošev, B. Kapun, The corrosion resistance of nitinol alloy in simulated physiological solutions: Part 1: The effect of surface preparation, Materials Science and Engineering C 32 (2012) 1087-1096. 
[20] I. Milošev, B. Kapun, The corrosion resistance of nitinol alloy in simulated physiological solutions: Part 2: The effect of surface treatment, Materials Science and Engineering C 32 (2012) 1068-1077.

[21] M. Es-Souni, M. Es-Souni, H. Fischer-Brandies, Assessing the biocompatibility of NiTi shape memory alloys used for medical applications, Analytical and Bioanalytical Chemistry 381 (2005) 557-567.

[22] G.T. Burstein, C. Liu, R.M. Souto, The effect of temperature on the nucleation of corrosion pits on titanium in Ringer's physiological solution, Biomaterials 26 (2005) 245-256.

[23] N.J. Hallab, A. Skipor, J.J. Jacobs, Interfacial kinetics of titanium- and cobaltbased implant alloys in human serum: metal release and biofilm formation, Journal of Biomedical Materials Research A 65 (2003) 311-318.

[24] A.J. Bard, M.V. Mirkin (Eds.), Scanning Electrochemical Microscopy, 2 ${ }^{\text {nd }}$. edition, CRC Press, Boca Raton, 2012.

[25] S.B. Basame, H.S. White, Scanning electrochemical microscopy of native titanium oxide films. Mapping the potential dependence of spatially-localized electrochemical reactions, Journal of Physical Chemistry 99 (1995) 16430-16435.

[26] S.B. Basame, H.S. White, Scanning electrochemical microscopy: measurement of the current density at microscopic redox-active sites on titanium, Journal of Physical Chemistry 102 (1998) 9812-9819.

[27] R. Zhu, C. Nowierski, Z. Ding, J.J. Noël, D.W. Shoesmith, Insights into grain structures and their reactivity on grade-2 $\mathrm{Ti}$ alloy surfaces by scanning electrochemical microscopy, Chemistry of Materials 19 (2007) 2533-2543.

[28] R. Zhu, Z. Qin, J.J. Noël, D.W. Shoesmith, Z. Ding, Analyzing the influence of alloying elements and impurities on the localized reactivity of titanium grade-7 by scanning electrochemical microscopy, Analytical Chemistry 80 (2008) 14371447.

[29] N. Casillas, S.J. Charlebois, W.H. Smyrl, H.S. White, Scanning electrochemical microscopy of precursor sites for pitting corrosion on titanium, Journal of The Electrochemical Society 140 (1993) L142-L145.

[30] N. Casillas, S. Charlebois, W.H. Smyrl, H.S. White, Pitting corrosion of titanium, Journal of The Electrochemical Society 141 (1994) 636-642. 
[31] L.F. Garfias-Mesias, M. Alodan, P.I. James, W.H. Smyrl, Determination of precursor sites for pitting corrosion of polycrystalline titanium by using different techniques, Journal of The Electrochemical Society 145 (1998) 2005-2010.

[32] G. Bolat, J. Izquierdo, J.J. Santana, D. Mareci, R.M. Souto, Electrochemical characterization of ZrTi alloys for biomedical applications, Electrochimica Acta 88 (2013) 447-456.

[33] G. Bolat, D. Mareci, R. Chelariu, J. Izquierdo, S. González, R.M. Souto. Investigation of the electrochemical behaviour of TiMo alloys in simulated physiological solutions, Electrochimica Acta 113 (2013) 470-480.

[34] J. Izquierdo, G. Bolat, D. Mareci, C. Munteanu, S. González, R.M. Souto. Electrochemical behaviour of ZrTi alloys in artificial physiological solution simulating in vitro inflammatory conditions, Applied Surface Science 313 (2014) 259-266.

[35] R. Chelariu, G. Bolat, J. Izquierdo, D. Mareci, D.M. Gordin, T. Gloriant, R.M. Souto, Metastable beta Ti-Nb-Mo alloys with improved corrosion resistance in saline solution, Electrochimica Acta 137 (2014) 280-289.

[36] A. Schulte, S. Belger, W. Schuhmann, Corrosion of NiTi shape-memory alloys: Visualization by means of potentiometric “constant-distance" scanning electrochemical microscopy. Materials Science Forum 394-395 (2002) 145-148.

[37] A. Schulte, S. Belger, M. Etienne, W. Schuhmann, Imaging localised corrosion of NiTi shape memory alloys by means of alternating current scanning electrochemical microscopy (AC-SECM), Materials Science and Engineering A 378 (2004) 523-526.

[38] D. Ruhlig, H. Gugel, A. Schulte, W. Theisen, W. Schuhmann, Visualization of local electrochemical activity and local nickel ion release on laser-welded $\mathrm{NiTi} /$ steel joints using combined alternating current mode and stripping mode SECM, Analyst 133 (2008) 1700-1706.

[39] S.E. Pust, D. Scharnweber, C.N. Kirchner, G. Wittstock, Heterogeneous distribution of reactivity on metallic biomaterials: scanning probe microscopy studies of the biphasic Ti alloy Ti6Al4V, Advanced Materials 19 (2007) 878-882.

[40] S.E. Pust, D. Scharnweber, S. Baunack G. Wittstock, Electron transfer kinetics at oxide films on metallic biomaterials - Scanning electrochemical microscopy studies of Ti6Al4V, Journal of The Electrochemical Society 154 (2007) C508C514. 
[41] A. Maho, F. Kanoufi, C. Combellas, J. Delhalle, Z. Mekhalif, Electrochemical investigation of nitinol/tantalum hybrid surfaces modified by alkylphosphonic self-assembled monolayers, Electrochimica Acta 116 (2014) 78-88.

[42] B. Yeum, Electrochemical Impedance Spectroscopy: Data Analysis Software, Echem Software, Ann Arbor, 2001.

[43] F.-R.F. Fan, C. Demaille, Preparation of tips for scanning electrochemical microscopy. In: Scanning Electrochemical Microscopy, $2^{\text {nd }}$ edition, A.J. Bard, M.V. Mirkin (Eds.). CRC Press, Boca Raton, 2012, Ch. 3.

[44] T.P Hoar, D.C Mears, Corrosion-resistant alloys in chloride solutions: materials for surgical implants, Proceedings of the Royal Society of London Series AMathematical and Physical Sciences 294 (1966) 486-510.

[45] D. Wallinder, J. Pan, C. Leygraf, A. Delblanc-Bauer, EIS and XPS study of surface modification of 316LVM stainless steel after passivation, Corrosion Science 41 (1999) 275-289.

[46] F. Mansfeld, Analysis and interpretation of EIS data for metals and alloys, Technical Report 26, Solartron-Schlumberger, Farnborough, 1993, p. 4.1-4.24.

[47] X. Cheng, S.G. Roscoe, Corrosion behavior of titanium in the presence of calcium phosphate and serum proteins, Biomaterials 26 (2005) 7350-7356.

[48] S.L. Assis, S. Wolynec, I. Costa, Corrosion characterization of titanium alloys by electrochemical techniques, Electrochimica Acta 51 (2006) 1815-1819.

[49] B.I. Wang, Y.F. Zheng, I.C. Zhao, Effects of Hf content and immersion time on electrochemical behaviour of biomedical Ti-22Nb-xHf alloys in $0.9 \% \mathrm{NaCl}$ solution, Materials and Corrosion 60 (2009) 330-335.

[50] J. Pan, D. Thierry, C. Leygraf, Hydrogen peroxide toward enhanced oxide growth on titanium in PBS solution: Blue coloration and clinical relevance, Journal of Biomedical Materials Research 30 (1996) 393-402.

[51] J. Pan, D. Thierry, C. Leygraf, Electrochemical and XPS studies of titanium for biomaterial applications with respect to the effect of hydrogen peroxide, Journal of Biomedical Materials Research 28 (1994) 113-122.

[52] A.J. Bard, L.R. Faulkner, Electrochemical Methods, Fundamentals and Applications, John Wiley \& Sons, New York, 2001, Ch. 5.

[53] R. Cornut, C. Lefrou, New analytical approximation of feedback approach curves with a microdisk SECM tip and irreversible kinetic reaction at the substrate, Journal of Electroanalytical Chemistry 621 (2008) 178-184. 
[54] J. Izquierdo, J.J. Santana, S. González, R.M. Souto, Uses of scanning electrochemical microscopy for the characterization of thin inhibitor films on reactive metals: the protection of copper surfaces by benzotriazole, Electrochimica Acta 55 (2010) 8791-8800.

[55] G. Ciurescu, J. Izquierdo, J.J. Santana, D. Mareci, D. Sutiman, S. González, R.M. Souto, Characterization of the localized surface chemical activity of Ti-Mo and Ti-Ta alloys for biomedical applications using scanning electrochemical microscopy, International Journal of Electrochemical Science 7 (2012) 74047424.

[56] J. Izquierdo, J.J. Santana, S. González, R.M. Souto, Scanning microelectrochemical characterization of the anti-corrosion performance of inhibitor films formed by 2-mercaptobenzimidazole on copper, Progress in Organic Coatings 74 (2012) 526-533.

[57] J.J. Santana, J. González-Guzmán, L. Fernández-Mérida, S. González, R.M. Souto, Visualization of local degradation processes in coated metals by means of scanning electrochemical microscopy in the redox competition mode, Electrochimica Acta 55 (2010) 4488-4494.

[58] S.A. Shabalovskaya, G.C. Rondelli, A.L. Undisz, J.W. Anderegg, T.D. Burleigh, M.E. Rettenmayr, The electrochemical characteristics of native Nitinol surfaces, Biomaterials 30 (2009) 3662-3671.

[59] J. Izquierdo, L. Martín-Ruíz, B.M. Fernández-Pérez, L. Fernández-Mérida, J.J. Santana, R.M. Souto, Imaging local surface reactivity on stainless steels 304 and 316 inacid chloride solution using scanning electrochemical microscopy and the scanning vibrating electrode technique, Electrochimica Acta 134 (2014) 167-175.

[60] J. Izquierdo, L. Martín-Ruíz, B.M. Fernández-Pérez, R. Rodríguez-Raposo, J.J. Santana, R.M. Souto, Scanning microelectrochemical characterization of the effect of polarization on the localized corrosion of 304 stainless steel in chloride solution, Journal of Electroanalytical Chemistry 728 (2014) 148-157.

[61] M. Pourbaix (Ed.), Atlas of Electrochemical Equilibria in Aqueous Solutions, Pergamon Press, Oxford, 1966.

[62] S.V. Lamaka, R.M. Souto, M.G.S. Ferreira, In situ visualization of local corrosion by scanning ion-selective electrode technique (SIET), in: A. Méndez-Vilas, J. Díaz (Eds.), Microscopy: Science, Technology, Applications and Education, Vol. 3. Formatex Research Center, Badajoz (Spain), 2010, pp. 2162-2173. 
Table 1. Electrochemical parameters determined from the potentiodynamic polarization curves measured for titanium and nitinol samples immersed in Ringer's solution at ambient temperature.

\begin{tabular}{|c|c|c|}
\hline & Titanium & Nitinol \\
\hline OCP vs. (Ag/AgCl/3M KCl) / V & $-0.340 \pm 0.013$ & $-0.211 \pm 0.029$ \\
\hline$j_{\text {corr }} / \mu \mathrm{A}$ cm$^{-2}$ & $0.171 \pm 0.060$ & $0.0400 \pm 0.0046$ \\
\hline$-\beta_{c} / \mathrm{V}$ decade $^{-1}$ & $0.198 \pm 0.019$ & $0.128 \pm 0.047$ \\
\hline$\beta_{a} / \mathrm{V}$ decade $^{-1}$ & $0.213 \pm 0.032$ & $0.270 \pm 0.026$ \\
\hline$j_{\mathrm{pass}} * / \mu \mathrm{A} \mathrm{cm} \mathrm{cm}^{-2}$ & $16.2 \pm 3.91$ & $8.24 \pm 6.99$ \\
\hline Pitting potential vs. (Ag/AgCl/3M KCl) / V & - & $0.538 \pm 0.106$ \\
\hline
\end{tabular}

*Determined at $+0.35 \mathrm{~V}$ vs. $\mathrm{Ag} / \mathrm{AgCl} / 3 \mathrm{M} \mathrm{KCl}$

Table 2. Impedance parameters of titanium (Ti) and nitinol (NiTi) samples in Ringer's solution.

\begin{tabular}{lcc}
\hline & Ti & NiTi \\
\hline$R_{\mathrm{s}} / \Omega \mathrm{cm}^{2}$ & 4.82 & 7.34 \\
$R_{\mathrm{ct}} / \mathrm{k} \Omega \mathrm{cm}^{2}$ & 50.6 & 280 \\
$Q_{\mathrm{dl}} \times 10^{5} / \mathrm{S} \mathrm{cm}^{-2} \mathrm{~s}^{n}$ & 11.6 & 2.98 \\
$n_{\mathrm{dl}}$ & 0.768 & 0.870 \\
$R_{\mathrm{ox}} / \mathrm{k} \Omega \mathrm{cm}^{2}$ & 8.37 & 0.355 \\
$Q_{\mathrm{ox}} \times 10^{5} / \mathrm{S} \mathrm{cm}^{-2} \mathrm{~s}^{n}$ & 22.9 & 4.40 \\
$n_{\mathrm{ox}}$ & 1 & 0.721 \\
\hline
\end{tabular}

Table 3. Film thicknesses estimated from EIS results measured for titanium and nitinol samples in Ringer's solution. A dielectric constant value of 65 was assumed.

\section{Film thickness / nm}

\begin{tabular}{lcc}
\hline & Inner “barrier film” & Outer “porous layer” \\
\hline Titanium & 4.4 & 8.6 \\
Nitinol & 1.1 & 1.6 \\
\hline
\end{tabular}


Table 4. Electrochemical parameters determined from the cyclic voltammograms in Figure 10. They were measured at a Pt microelectrode placed $15 \mu \mathrm{m}$ over the centre of a nitinol sample polarized at $+0.40 \mathrm{~V}$ vs. $\mathrm{Ag} / \mathrm{AgCl} / 3 \mathrm{M} \mathrm{KCl}$ during immersion in Ringer's solution $+0.5 \mathrm{mM}$ ferrocenemethanol.

\begin{tabular}{lcc}
\hline & $\boldsymbol{E}_{\mathbf{a}}$ vs. $(\mathbf{A g} / \mathbf{A g C l} / \mathbf{3 M ~ K C l})$ & $\boldsymbol{E}_{\mathbf{c}}$ vs. $(\mathbf{A g} / \mathbf{A g C l} / \mathbf{3 M ~ K C l}) /$ \\
& $/ \mathbf{V}$ & $\mathbf{V}$ \\
\hline Scan \#1 & 0.371 & 0.052 \\
Scan \#2 & 0.363 & 0.024 \\
Scan \#3 & 0.431 & 0.035 \\
Scan \#4 & 0.400 & 0.038 \\
Scan \#5 & 0.532 & 0.086 \\
\hline
\end{tabular}
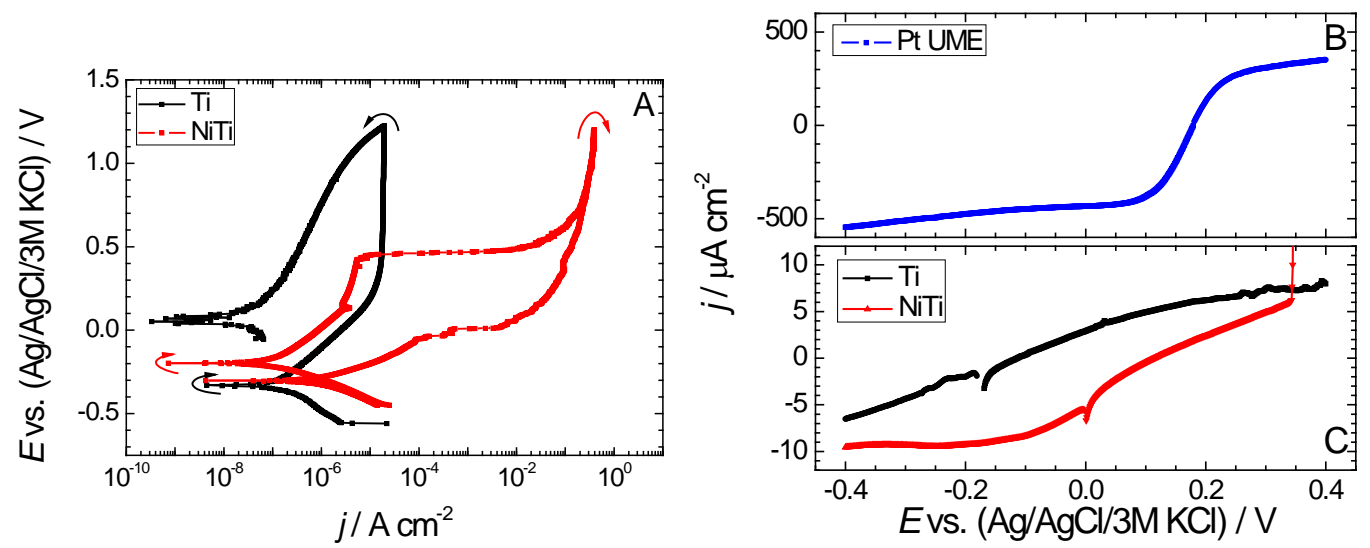

Figure 1.

Potentiodynamic polarization of titanium (Ti) and nitinol (NiTi) samples in Ringer's physiological solution: (A) unmodified solution, and (C) solution containing the ferrocenemethanol/ ferrocenium couple. (B) Voltammetric response of a $\mathrm{Pt}$ microelectrode $(a=12.5 \mu \mathrm{m})$ in modified Ringer's solution. Arrows in (A) indicate the direction of the potential scans applied to the samples. Scan rate: $1 \mathrm{mV} \mathrm{s}^{-1}$. 


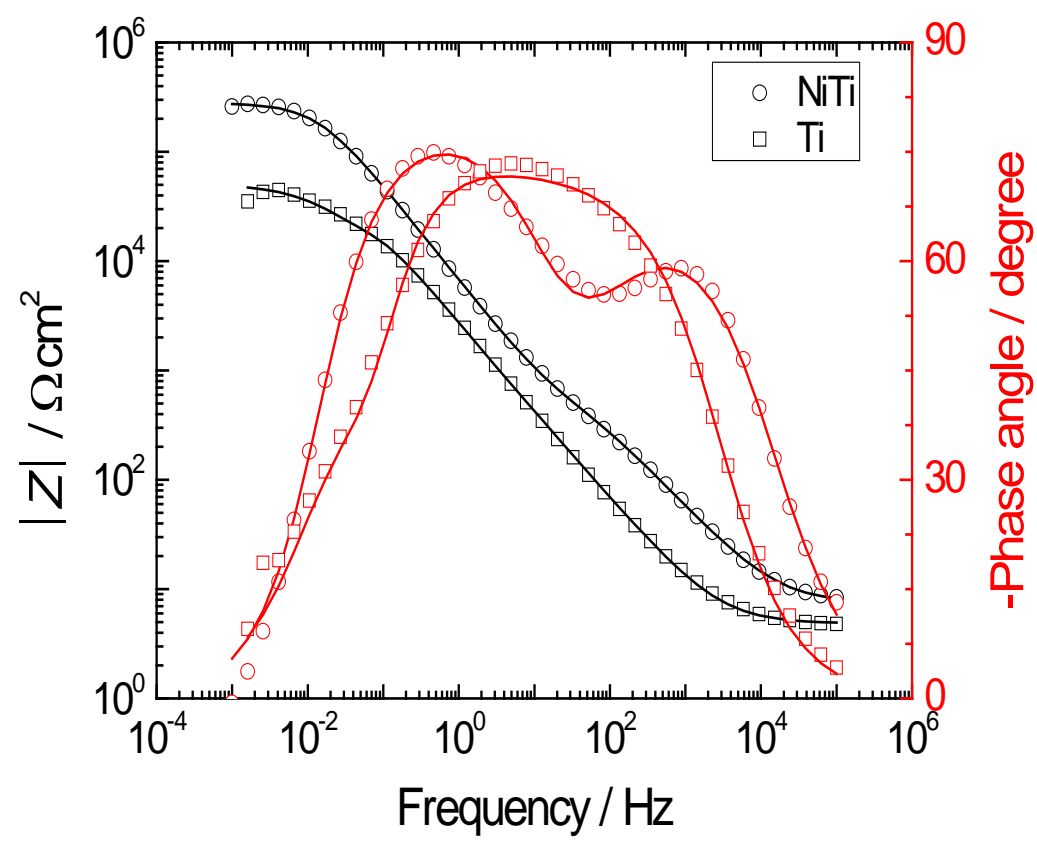

\section{Figure 2.}

Bode spectra for titanium (Ti) and nitinol (NiTi) samples after 90 min in Ringer's solution, measured at their OCP. Measured (discrete points) and fitted (solid lines) data.

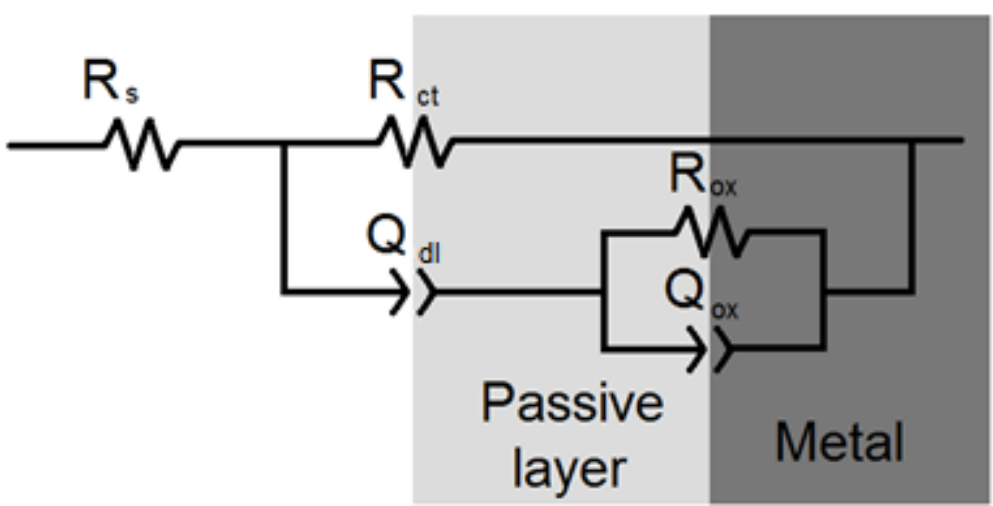

Figure 3.

Equivalent circuit (EC) used for the interpretation of the measured impedance spectra: two-layer model of a sealed porous surface film with two time constants. 

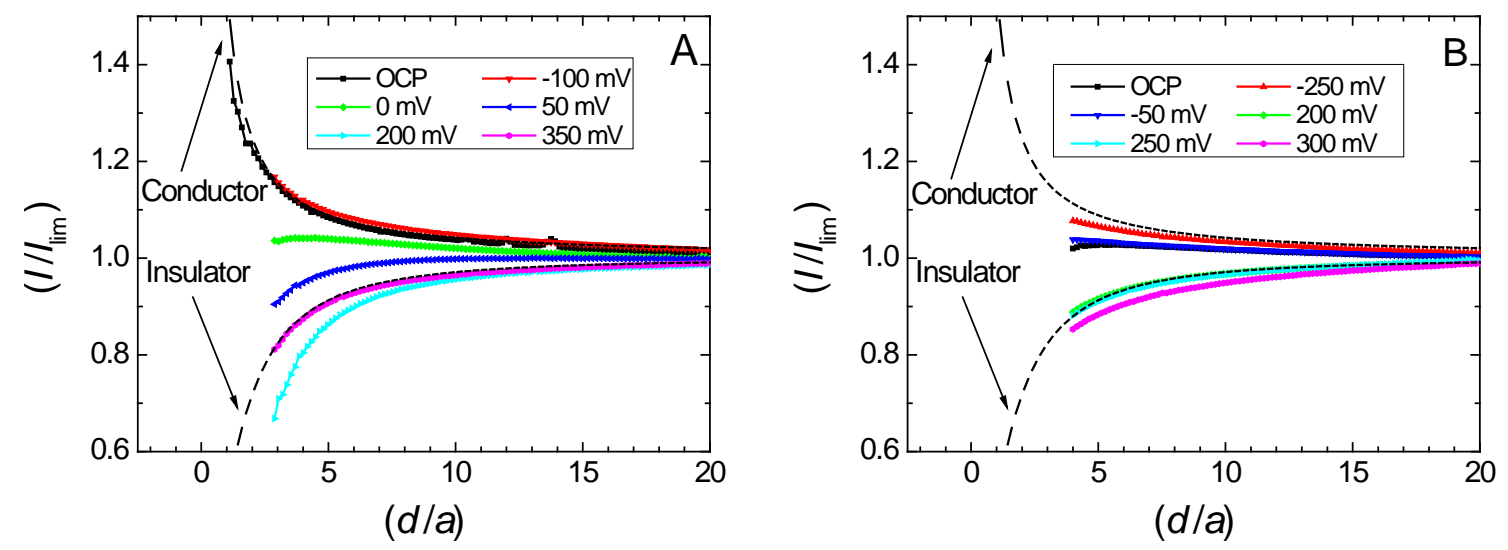

\section{Figure 4.}

Z-approach curves measured with the Pt microelectrode obtained over (A) titanium and (B) nitinol samples immersed in Ringer's solution $+0.5 \mathrm{mM}$ ferrocenemethanol. The metallic samples were potentiostatically polarized as indicated in the plots. Theoretical curves for conductive and insulating materials are also drawn in the graphs. Tip potential: $+0.50 \mathrm{~V}$ vs. $\mathrm{Ag} / \mathrm{AgCl} / 3 \mathrm{M} \mathrm{KCl}$; scan rate: $2 \mu \mathrm{m} \mathrm{s}^{-1}$; tip radius: $12.5 \mu \mathrm{m} . \mathrm{I} / \mathrm{Im}$ is the dimensionless tip current, and $d / a$ is the dimensionless tip-sample distance.
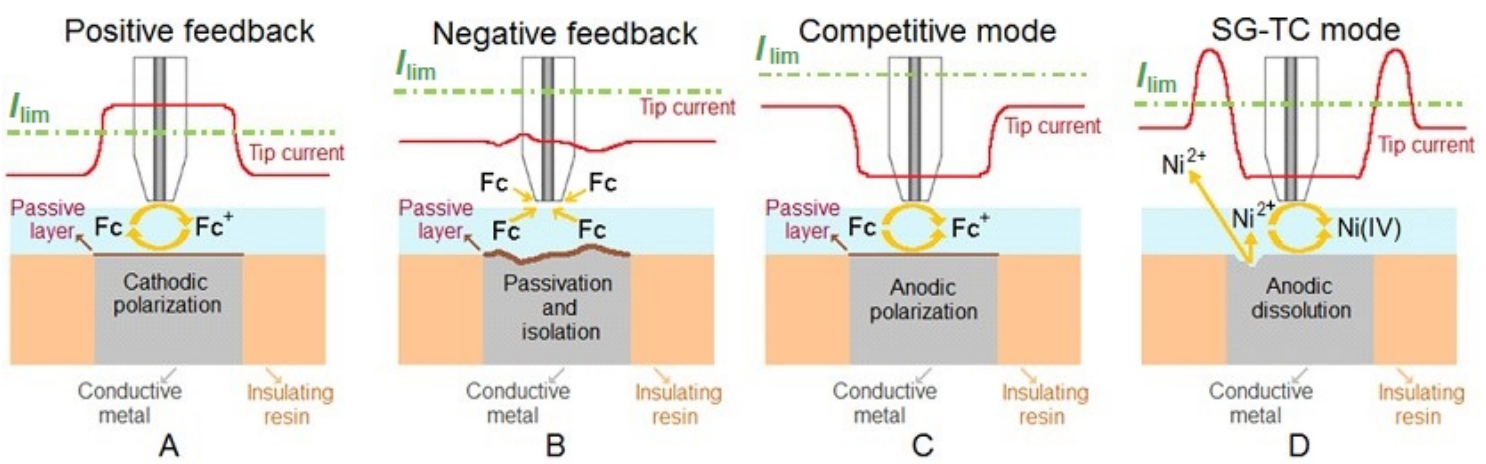

Figure 5.

Electrochemical responses observed for the tip current as a function of substrate polarization during amperometric SECM operation over titanium (Ti) and nitinol (NiTi) samples exposed to Ringer's solution containing ferrocenemethanol as redox mediator. (A) Positive feedback effect recorded over cathodically polarized conductive areas because of ferrocenium reduction on the substrate; (B) negative feedback effect recorded over the oxide-covered surface, which blocks the diffusion pathways for ferrocenemethanol from the bulk of the solution; (C) competitive effect towards ferrocenemethanol oxidation established between the tip and anodically polarized conducting regions formed on the substrate; and (D) substrate generation-tip collection effect recorded over anodically polarized nitinol due to the onset of pitting corrosion (the underlying metal becomes exposed to the electrolyte, leading to the release of soluble nickel (II) ions, that are further oxidized to $\mathrm{Ni}(\mathrm{IV})$ at the tip). The tip current plots have been drawn using arbitrary units. 

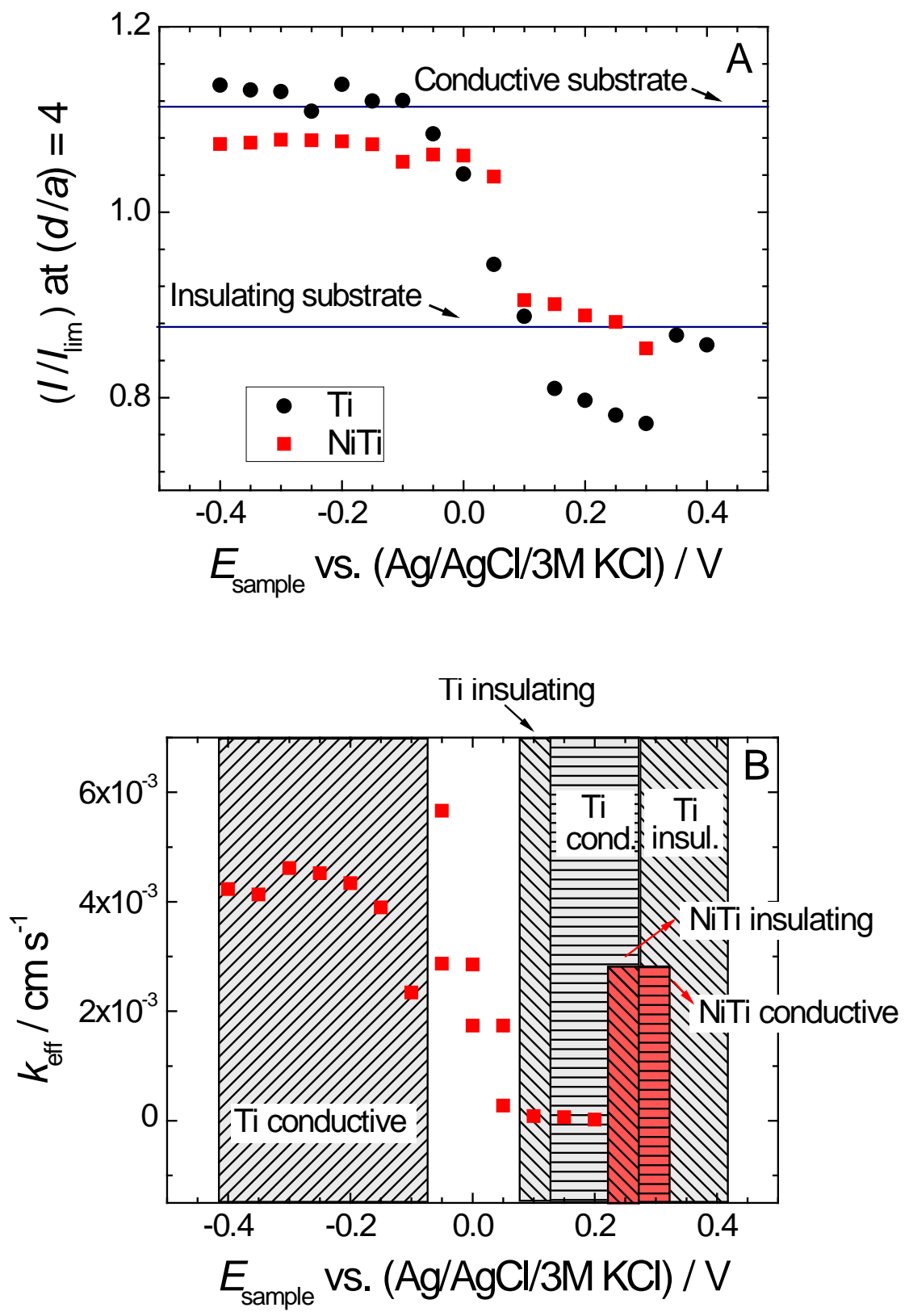

\section{Figure 6.}

Variation with the substrate potential of: (A) the normalized current value taken at $d / a=$ 4 in the Z-approach curves given in Figure 3, and (B) the calculated kinetic rate constant for $\mathrm{Fc}^{+}$electro-reduction at the substrates. The horizontal limits drawn in (A) indicate the theoretical result for conductive and insulating surfaces. The filled regions in (B) give the potential intervals where the metal samples exhibit fully conductive or insulating characteristics towards ferrocenemethanol regeneration. 

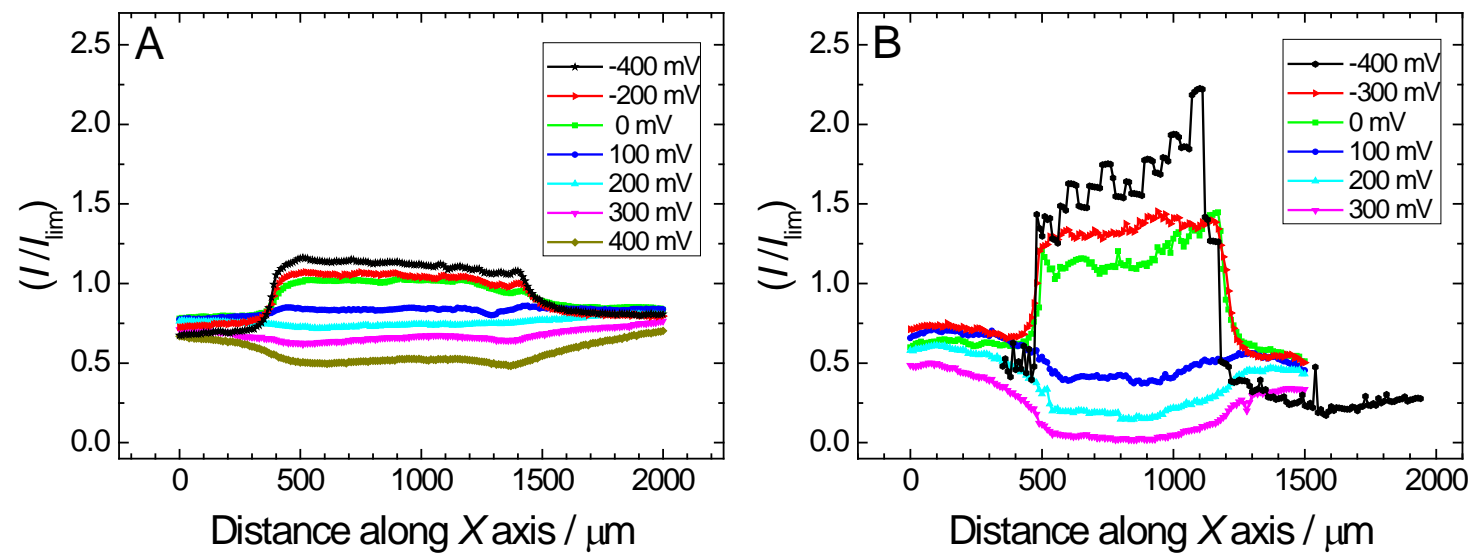

\section{Figure 7.}

Scan lines measured above (A) titanium and (B) nitinol samples immersed in Ringer's solution $+0.5 \mathrm{mM}$ ferrocenemethanol for various polarizations of the samples as indicated in the plots. Tip potential: $+0.50 \mathrm{~V}$ vs. $\mathrm{Ag} / \mathrm{AgCl} / 3 \mathrm{M} \mathrm{KCl}$; scan rate: $10 \mu \mathrm{m} \mathrm{s}^{-1}$; tip radius: $6.25 \mu \mathrm{m} . \mathrm{I} / \mathrm{Im}$ is the dimensionless tip current.

A

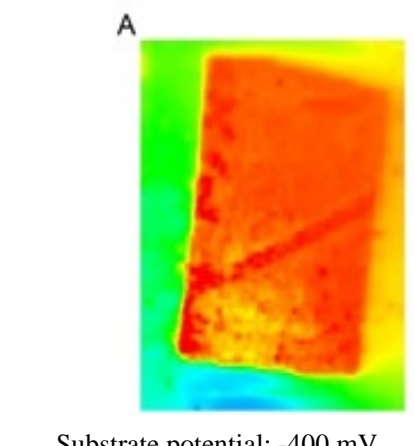

B

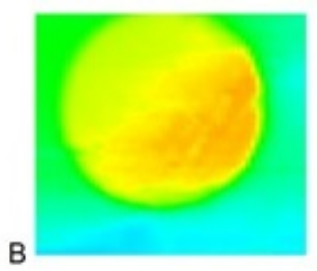

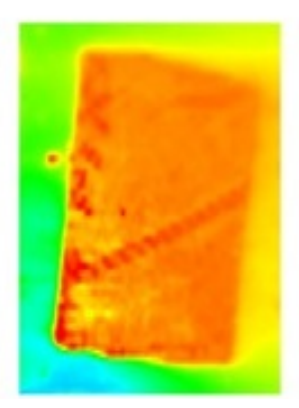

$-200 \mathrm{mV}$

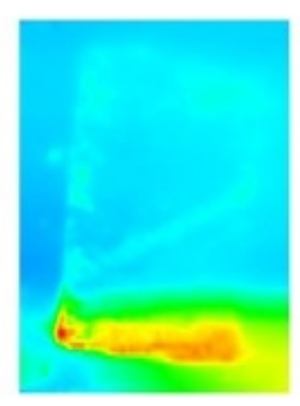

$0 \mathrm{mV}$
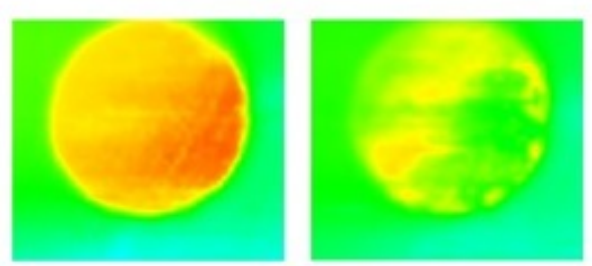

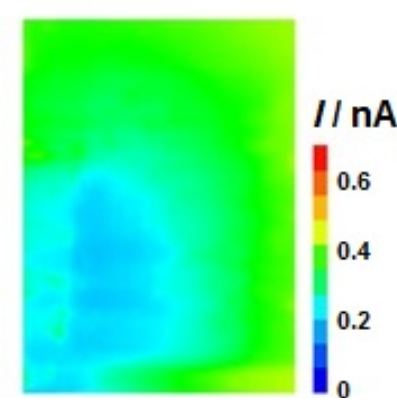

$+200 \mathrm{mV}$

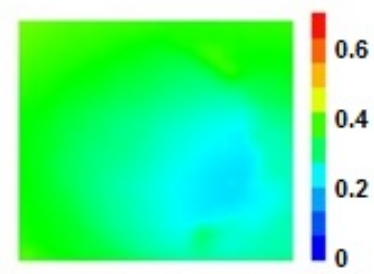

\section{Figure 8.}

Images generated by SECM of (A) titanium and (B) nitinol samples immersed in Ringer's solution $+0.5 \mathrm{mM}$ ferrocenemethanol for the polarizations of the samples indicated in the graph. Substrate potential indicated in the intermediate row. Tip potential: $+0.50 \mathrm{~V}$ vs. $\mathrm{Ag} / \mathrm{AgCl} / 3 \mathrm{M} \mathrm{KCl}$; scan rate: $30 \mu \mathrm{m} \mathrm{s}^{-1}$; tip radius: $6.25 \mu \mathrm{m}$. Scan dimensions: (A) $1600 \mu \mathrm{m} \times 2200 \mu \mathrm{m}$, and (B) $1000 \mu \mathrm{m} \times 1200 \mu \mathrm{m}$. Limiting current in bulk solution: (A) 0.638, and (B) $0.665 \mathrm{nA}$. 

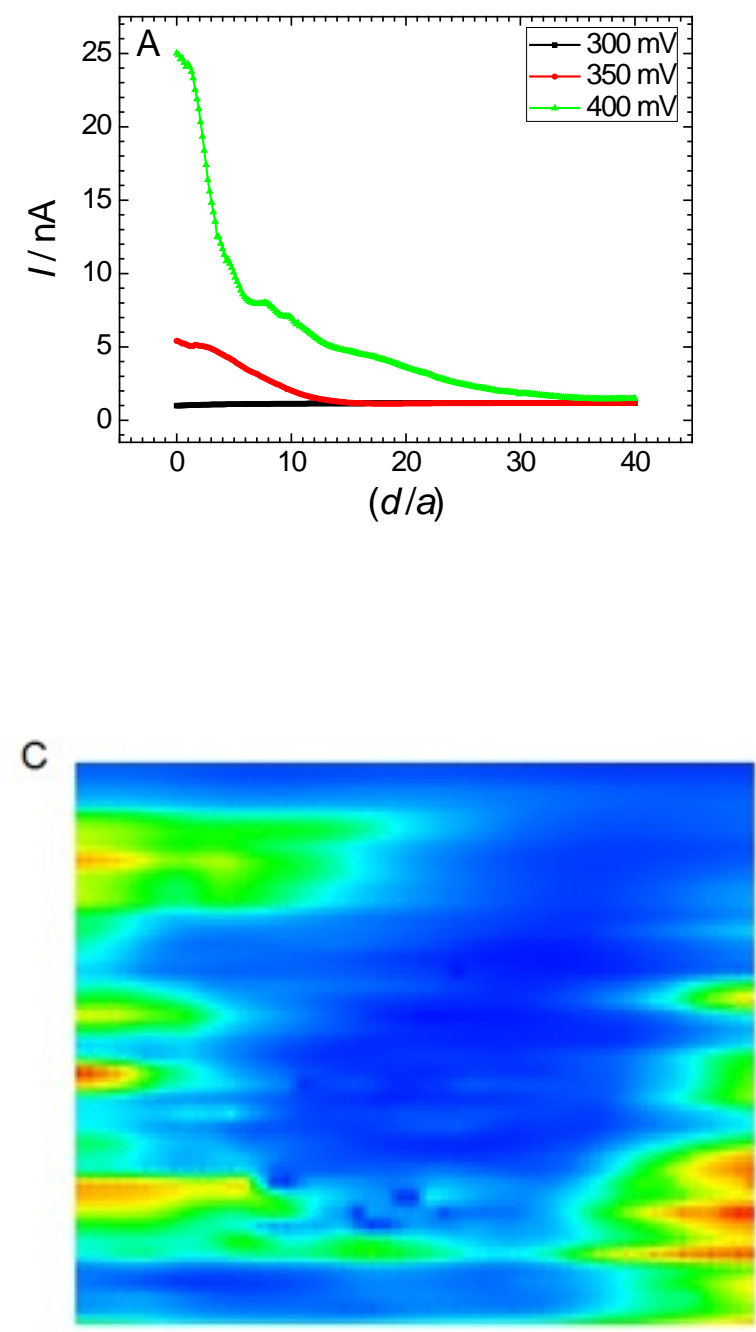

// nA

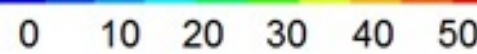

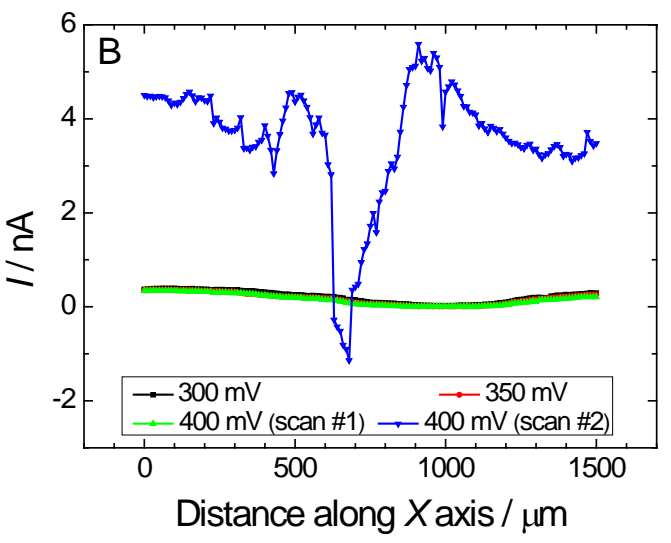

D

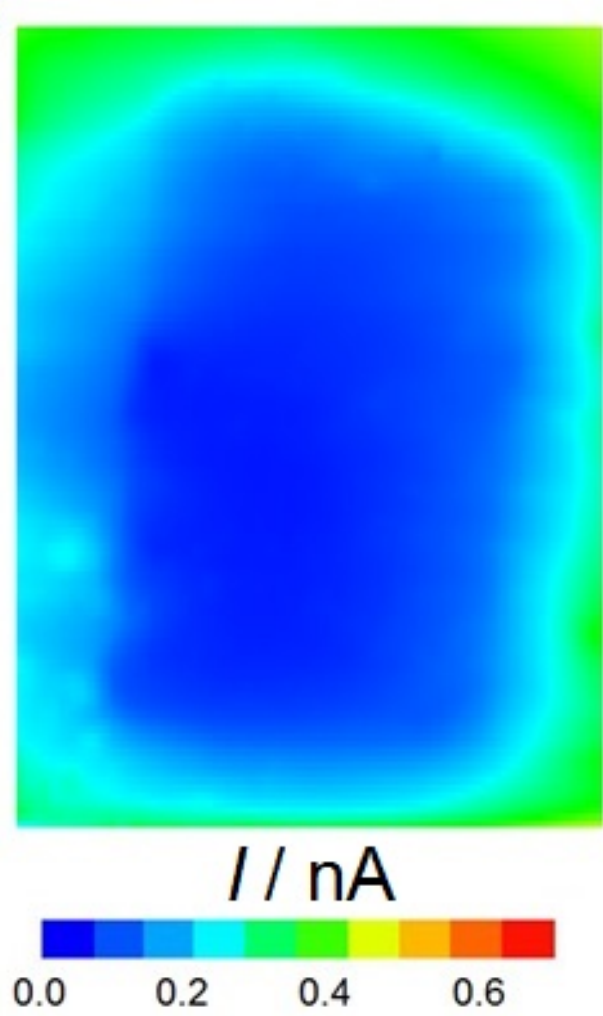

\section{Figure 9.}

(A) Z-approach curves, (B) scan lines and (C,D) images measured over (A,B,C) nitinol and (D) titanium samples immersed in Ringer's solution $+0.5 \mathrm{mM}$ ferrocenemethanol for the polarizations of the samples indicated in the plots. Substrate potential: (A,B) given in the legend, (C) +0.35 , and (D) $+0.40 \mathrm{~V}$ vs. Ag/AgCl/3M KCl. Tip potential: $+0.50 \mathrm{~V}$ vs. Ag/AgCl/3M KCl; scan rate: (A) $2 \mu \mathrm{m} \mathrm{s}^{-1}$, (B) $10 \mu \mathrm{m} \mathrm{s}^{-1}$, and (C) $30 \mu \mathrm{m} \mathrm{s}^{-1}$; tip radius: $6.25 \mu \mathrm{m}$. Scan dimensions: (C) $1000 \mu \mathrm{m} \times 1200 \mu \mathrm{m}$, and (D) $1600 \mu \mathrm{m} \times$ $2200 \mu \mathrm{m}$. Limiting current: (C) 0.665 and (D) $0.638 \mathrm{nA}$. 


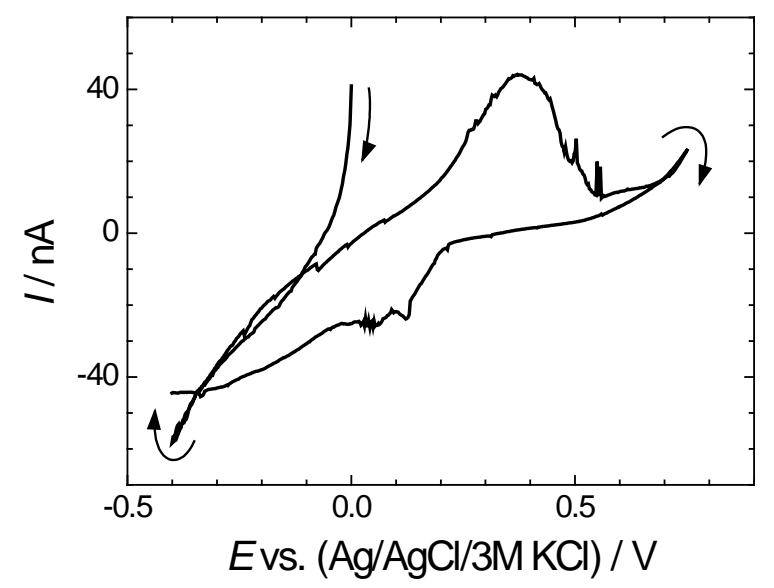

\section{Figure 10.}

Cyclic voltammograms obtained with the Pt microelectrode located at $15 \mu \mathrm{m}$ distance over the centre of a nitinol sample polarized at $+0.40 \mathrm{~V}$ vs. $\mathrm{Ag} / \mathrm{AgCl} / 3 \mathrm{M} \mathrm{KCl}$ during immersion in Ringer's solution $+0.5 \mathrm{mM}$ ferrocenemethanol. Scan rate: $10 \mathrm{mV} \mathrm{s}^{-1}$. Tip radius: $6.25 \mu \mathrm{m}$. 